\title{
Friction characteristics of confined inflatable structures
}

\author{
Eduardo M. SOSA ${ }^{1, *}$, Gregory J. THOMPSON ${ }^{2}$, Ever J. BARBERO ${ }^{2}$, Subhadeep GHOSH ${ }^{1}$, Kevin L. PEIL ${ }^{2}$ \\ ${ }^{I}$ Department of Civil and Environmental Engineering, West Virginia University, Morgantown, WV 26506-6103, USA \\ ${ }^{2}$ Department of Mechanical and Aerospace Engineering, West Virginia University, Morgantown, WV 26506-6106, USA \\ Received: 10 June 2014 / Revised: 26 September 2014 / Accepted: 14 November 2014 \\ (C) The author(s) 2014. This article is published with open access at Springerlink.com
}

\begin{abstract}
The availability of high-strength fabrics and progress in the development of large-scale inflatable technology made possible the creation of temporary and quickly deployable structures for protection of underground infrastructure. Inflatable structures are relatively lightweight and portable, and can maintain the required rigidity while in operation. These benefits have prompted the development of inflatable structures for use in confined spaces, such as tunnels and large-diameter pipes to act as barriers for containing flooding with minimal infrastructure modification. This work presents experimental results obtained from the evaluation of frictional characteristics of the fabric material that constitute the structural membrane of confined inflatable structures developed for protection of underground transportation tunnels and other large conduits. Friction tests at coupon level and slippage tests in a reduced-scale inflatable structure were performed in order to evaluate the frictional characteristics of Vectran webbings. Tests at coupon level were performed to determine the friction coefficient for different surface types and conditions. Tests with the reduced-scale inflatable structure contributed to the understanding of the friction characteristics at system level when subjected to different pressurization or depressurization sequences designed to induce slippage. Test results indicate that friction coefficient values at coupon level are about 29 percent higher than values derived from reduced-scale tests.
\end{abstract}

Keywords: friction; fabric materials; inflatable structures; slippage; Vectran

\section{Introduction}

In recent years, the availability of high-strength fabrics and progress in the development of large-scale inflatable technology has made possible the creation of temporary and quickly deployable structures for protection of underground infrastructure. Inflatable structures offer benefits such as being relatively lightweight and portable, maintaining the necessary rigidity while in operation, and having a relatively reduced production and installation cost compared to rigid, fixed gates. These benefits have prompted the use of inflatable structures in confined spaces, such as pipes and tunnels, to act as barriers for containing propagation of smoke or flooding with minimal infrastructure modification [1].

* Corresponding author: Eduardo M. SOSA.

E-mail: Eduardo.Sosa@mail.wvu.edu
Tunnel safety, integrity, and resilience are subjects of special concern to transportation authorities of the United States [2,3] and in several other countries, not only because tunnels are of difficult and limited accessibility, but also because most potential threats (e.g., fires, flooding, and noxious substances) compromise the integrity of the entire connecting system as the threat can spread along it. Examples of such extraordinary events include the 1992 Chicago freight tunnel flood [4], which forced the shutdown of the subway system, caused damage to numerous businesses, and required the evacuation of about 250,000 people from the area. The 2003 flooding of the Midtown Tunnel in Virginia, caused by Hurricane Isabel, in which about 44 million gallons (167 million liters) of water from the Elizabeth River flooded the tunnel system in just 40 minutes. The flooding left the tunnel damaged and closed for nearly a month 
[5]. Most recently, in New York City, seven subway tunnels under the East River as well as three road tunnels flooded during Hurricane Sandy and remained inoperable for several days [6]. These events have demonstrated that conventional emergency sealing systems are not always installed or operational during the occurrence of extraordinary events, thus the constant necessity of research to mitigate vulnerabilities or, at least, to minimize the consequences of those events.

To date, inflatable technology has been used in several environments to seal tunnel segments and serve as temporary barriers. For example, large-scale tunnel plugs were tested and installed in the London subway system to block smoke spread and limit oxygen supply to tunnel fires [7]. In another instance, a 7-meter diameter plug was filled with water and used in a uranium mine to stop flooding [8]. Most recently, West Virginia University (WVU) has been conducting research in the area of high-pressure confined inflatable plugs that can be rapidly deployed and pressurized to contain tunnel flooding $[9,10]$. Under the Department of Homeland Security Science and Technology Directorate's Resilient Tunnel project, WVU advanced a solution consisting of one or more inflatable plugs that can be placed at different locations along a tunnel. The resilient tunnel plug (RTP) system is designed to be remotely activated when a threatening event is detected, which triggers the deployment and inflation of one or more of the inflatables to isolate and seal the tunnel sections of concern. The sealing capacity is controlled by the ability of the inflatable to conform to the inner perimeter of the tunnel section while being pressurized. The external pressure (orig- inated by flooding or fumes) is equilibrated by friction forces generated at the contact surfaces $[1,11,12]$.

The RTP project has progressed in stages from a proof-of-concept, air-inflated prototype $[9,10]$ to reduced- and full-scale prototypes pressurized with water and subjected to backpressure for flooding simulations [11-13]. As part of this project, several full-scale tests were completed to evaluate the ability of a prototype inflatable plug to remain stable in a tunnel section while containing propagation of flooding pressure. Experiments were conducted in specially constructed testing facilities at WVU in which a tunnel mock-up resembled a typical subway tunnel section retrofitted to receive an inflatable plug. Experiments consisted of developing packing and deployment sequences, followed by inflation, pressurization, and flooding simulations, as illustrated in Fig. 1. Variables studied at full scale included measurements of the level of conformity of the inflatable to the tunnel section, which is critical to ensure proper sealing of the tunnel segment, measurement of leakage rates, and the stability of the system for design pressures $[11,12]$. Even though these tests demonstrated the viability and stability of the system for design pressures, no further full-scale testing was performed to assess the slippage characteristics of the inflatable plug. In these tests, the system was not taken beyond required operational parameters and design conditions; in terms of the strength of the membrane material or frictional resistance, design limitations were not evaluated. Additional tests would have involved inducing slippage failure by either increasing the flooding pressure or by gradually depressurizing the inflatable plug. Both alternatives would have required
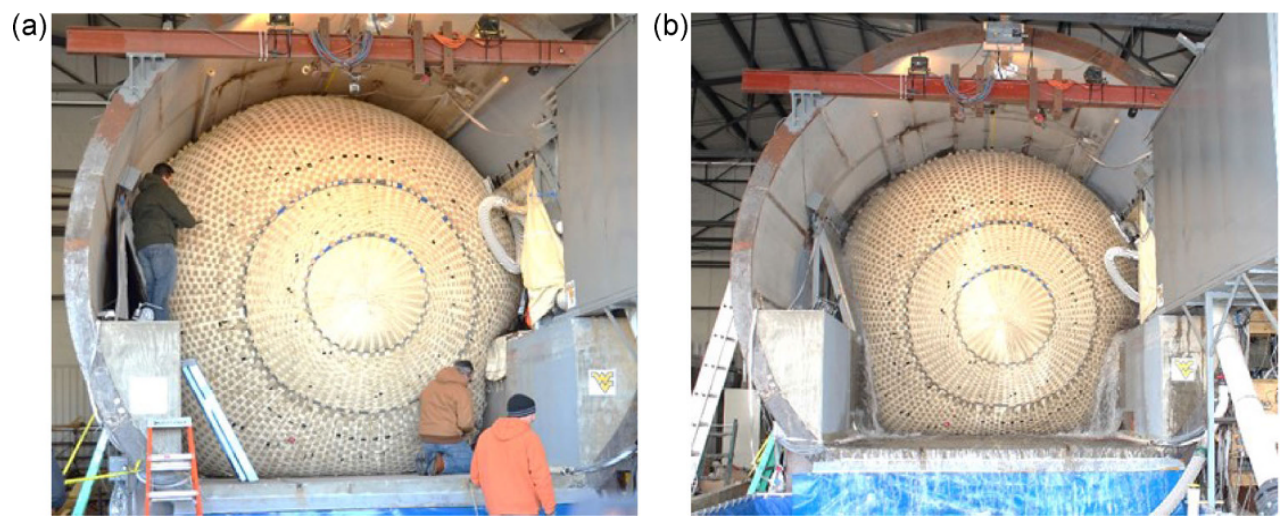

Fig. 1 Testing of full-scale prototype: (a) Conformity evaluation; (b) flooding simulation [11, 12]. 
additional test equipment and safety measures that the testing facilities were not prepared to carry out. Therefore, evaluations at a reduced scale were imperative to understand the slippage characteristics of the confined inflatable. In effect, the evaluation of slippage characteristics at reduced scale was necessary before manufacturing full-scale prototypes in order to confirm the structural performance and frictional properties of the design.

The evaluation of sliding friction of contacting materials at different scales has been performed intensively in the past. The fast development of highly sophisticated measuring technology allowed the investigation of frictional mechanisms at nano, micro and macro scales. Most of the studies about the influence of the scale on frictional properties focused on metals, alloys and ceramics for which elastoplastic material properties influence the frictional characteristics of the materials in contact. From these studies, different new theories describing the contact problem and frictional mechanisms have been proposed [14-22]. In this regard, Paggi and Carpinteri [14] present a compilation of current models that attempt to describe frictional behaviors from planetary scale to micro or nano scales with two opposite trends depending upon the scale under consideration. They indicate that weak and strong behavior at very large and very small scales, respectively, suggest that friction is scale-dependent, and the theories that describe quite well the phenomenon at one scale fail when applied to other scales. They concluded that, even after centuries of research, there is a lack of a reliable model that can predict the frictional characteristics between any given pair of sliding surfaces. According to them, despite that the coefficient of friction is often considered to be a constant for a given material pair under specific testing conditions, recent experiments have put in evidence that the friction coefficient is size-scale dependent and contradicts to what is known on the macroscopic scale. Brushan and Nosonovsky $[15,16]$ also offer a compilation of friction data obtained on the nano and micro scales in the past decades. They report that for tests performed on silicon, graphite and other materials, the coefficient of friction values on the nanoscale are about half to one order of magnitude lower than on the micro scale, concluding that friction values are scale dependent. They attributed the difference to the type of contact present at different scales. On the nanoscale, the contacts are predominantly elastic, and adhesion is the main contribution to friction. On a micro scale, contacts are predominantly plastic, and deformation is an important factor in the determination of the real area of contact.

At the opposite level, on a macro scale, and as pointed out by Chiaia [17], engineers have been usually content with the classical laws of Coulomb [18] and Amontons [19]. In the classical laws, the frictional force that resists sliding at an interphase is proportional to the normal load; however, and less intuitively, the amount of friction force is not dependent on the apparent area of contact. This second hypothesis was later updated by Bowden and Tabor [20] who found that although friction is independent of the apparent macroscopic area, it is proportional to the true contact area and therefore results primarily from adhesive bonding at true contact points. The number and type of contact points are a function of the roughness of the surface. Real surfaces are rough at the micro and even at the macro and meso scales, and the characteristics of the asperities influence the frictional behavior of the materials in contact. Chiaia [17] points out that the role of the roughness has been extensively investigated with opposite conclusions. For example, friction can increase when two opposing surfaces are made smoother-as in the case of highly polished metals - and, friction can also increase with roughness when interlocking effects among asperities come into play. Chiaia [17] attributes the apparent contradiction to the "effect of scale lengths" that seems to be of crucial importance in the frictional behavior of two materials in contact.

Considering that the present work is focused on the evaluation at a macro level of the frictional characteristics of textile material in contact with hard surfaces, Gupta [21] indicate that the behavior of textile yarns and fabrics is different than the behavior of solid bodies. Moreover, Kovar et al. [22] pointed out the influence of the scale on the evaluation of the frictional characteristics of textile material. They indicate that the frictional behavior is the result of contributions of different levels of organization within the structure of contacting materials: (1) at nano- 
level-due to bonds and forces between particles (atoms, molecules); (2) micro-level-due to surface morphology of fibers; (3) macro-level-geometries of the assembly (yarn and fabric); and (4) environmental level due to influence of air, moisture and finish at the surfaces. The macro level is of particular interest for this work since it deals with the impact of the surface unevenness of a yarn or a fabric has on friction. Compared to the degree of surface roughness of an individual fiber, that of a yarn or fabric is higher and so the impact of it on friction is, therefore, stronger. Besides, when a flat textile is placed over a frictional surface-such as steel, ceramic or another textilecontact is made by fibers over several small regions. When a tangential force is applied, the fibers may move or deform even before frictional resistance is overcome. According to Kovar et al. [22], typically, the slip will start to occur gradually at contact points and spread over a series of small steps. The result of this behavior will be that the higher the textile structure is in the hierarchy, being the lowest at chain molecules and the highest at fabric level, the lower will be the presence of the stick-slip phenomena in the friction profile.

This work presents a compilation of experimental results obtained from the evaluation of the frictional characteristics of fabric material rubbing against concrete material with different surface roughness. The fabric material is a sort of unconventional fabric since it was created from Vectran webbings organized in a plain weave fashion. The evaluation of friction was performed at a macro-scale level. It started at coupon level with single Vectran webbing, continued with specimens of the same Vectran webbings in a three by four woven arrangement, and ended with a reduced-scale prototype of a confined inflatable structure with the same Vetran webbing woven and arranged as found in the full scale prototype. The order of magnitude of the apparent area of contact of testing specimens ranged from $10^{1}$ to $10^{4}$ (in $\mathrm{cm}^{2}$ ) for the results reported herein. At coupon level, static friction coefficients were obtained from horizontal sliding tests on flat concrete surfaces of varying roughness, whereas, at reduced scale level, friction coefficients were obtained from slippage tests in a cylindrical pipe of constant surface roughness.

\section{Friction tests at coupon level}

\subsection{Materials}

The membrane of the prototype shown in Fig. 1 consists of a three-layer system comprised of an internal bladder, an intermediate fabric restraint, and an external webbing restraint. This multilayer fabric configuration is derived from aerospace applications as described in Ref. [23]. A close view of each layer is illustrated in Fig. 2. In this design, the bladder is the innermost layer of the construction and is in direct contact with the fluid used for inflation and pressurization. The function of the fabric restraint is to act as a middle layer that protects the internal bladder. The outermost layer is a macro-fabric comprised of woven webbings designed to carry out membrane stresses created by the pressurization and friction forces created by the interaction with the tunnel section once the inflatable is deployed and operational. Structurally, the outer layer is the most important since it carries out the pressurization loads. The two inner layers are oversized so they do not carry membrane stresses but are watertight and contribute to the mass and volume of the inflatable structure. The webbings that form the macro-fabric are woven in a plain weave pattern using $54 \mathrm{~mm}$ wide, $3 \mathrm{~mm}$ thick webbings with a nominal maximum tensile strength of $2,100 \mathrm{~N} / \mathrm{mm}$. Figure 3(a) shows a close view of the herringbone pattern of an individual webbing.

These webbings are manufactured with Vectran fibers, which are produced from a high-performance thermoplastic multifilament yarn spun from liquid crystal polymers (LCP) [24]. Key properties of the Vectran material that make it suitable for the proposed application are its high strength and tensile

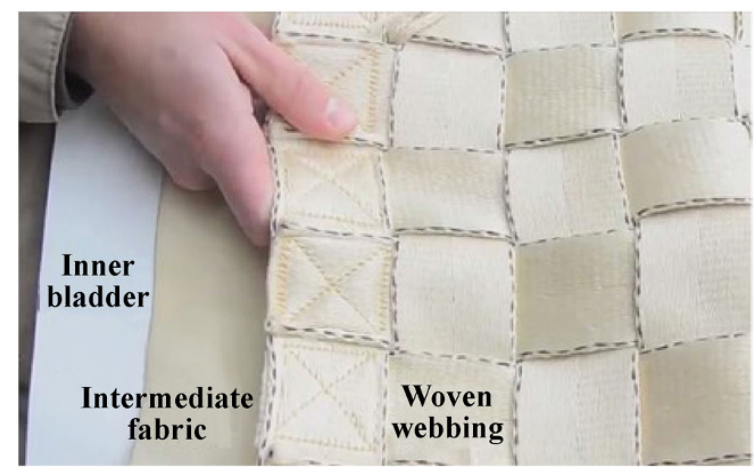

Fig. 2 Membrane configuration used in testing prototypes [13, 23]. 
(a)

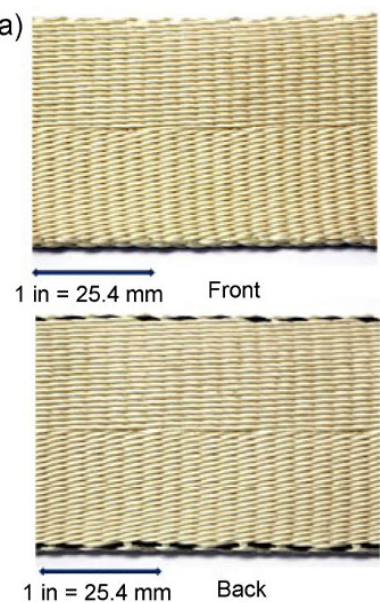

(b)

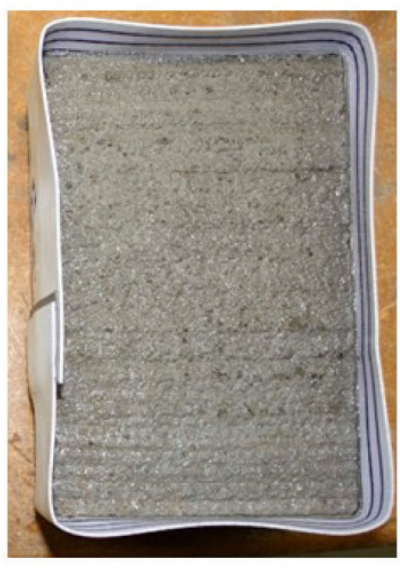

(c)

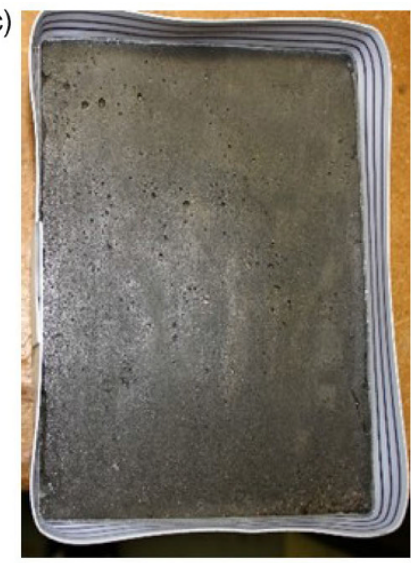

Fig. 3 Materials: (a) Vectran webbing; (b) rough concrete surface (ICRI-CSP \#4); (c) smooth concrete surface (ICRI-CSP \#1) [25].

modulus, which are critical to resisting membrane stresses originated by the pressurization; its high abrasion resistance to endure frictional forces during the deployment and sealing of the tunnel section; and its flexibility, which allows compact folding patterns for temporary or long-term storage while awaiting deployment.

The design and manufacturing of prototypes tested in Refs. [11,12] required the evaluation of friction properties of Vectran webbings rubbed against concrete surfaces with roughness that can be expected in typical concrete liners used in underground tunnels or similar large conduits. Two concrete surface finishes were selected for evaluation of friction characteristics: one denominated "rough concrete" (CSP \#4) and the other one denominated "smooth concrete" (CSP \#1), where the CSP number corresponds to the concrete surface preparation (CSP) standard created by the International Concrete Repair Institute (ICRI) [25]. In order to perform friction evaluations, concrete blocks that were $15 \mathrm{~cm}$ wide, $20 \mathrm{~cm}$ long, and $2 \mathrm{~cm}$ thick, were manufactured for the tests. One of the $15 \times 20$ surfaces of these blocks was prepared according to the selected CSP numbers. Figures 3(b) and 3(c) illustrate the concrete blocks with the surfaces used for the friction tests.

\subsection{Testing apparatus for single and woven webbings}

Initially, and with the objective of understanding of the friction characteristics of Vectran webbing, friction tests were performed using only single segments of material under different surface conditions to obtain static friction coefficients. The friction coefficient is a property that is strongly dependent on the system configuration, such as the types of surfaces, combination of loads applied to the surfaces, and lubrication effect of present liquids, among others [21, 26]. Since no standard exists for evaluation of friction of webbing material, a customized test setup was developed to reproduce-as close as possible-the conditions required in actual applications.

The testing machine used in previous friction tests with fabrics [1] was refitted for performing tests with single and woven webbings. The test setup consisted of a sled that held the base material and slid horizontally beneath a fixed test specimen to determine the friction coefficient between them. The sled held the concrete blocks described previously, or other piece of pre-tensioned webbing as illustrated in Figs. 4(a) and 4(b). The test specimen was held with a specialized fixture designed to hold the webbing under tension in order to simulate the stress that the webbing would be subjected to as part of the outer layer of the inflatable structure shown in Fig. 1. The pre-tensioning fixture was connected to a column that held the weights added to generate a normal force that simulated the contact pressure applied to the actual inflatable structure.

For the tests, the pre-tensioning fixture with the webbing specimen was held stationary. The sled was pushed by an electrical linear actuator moving at a 

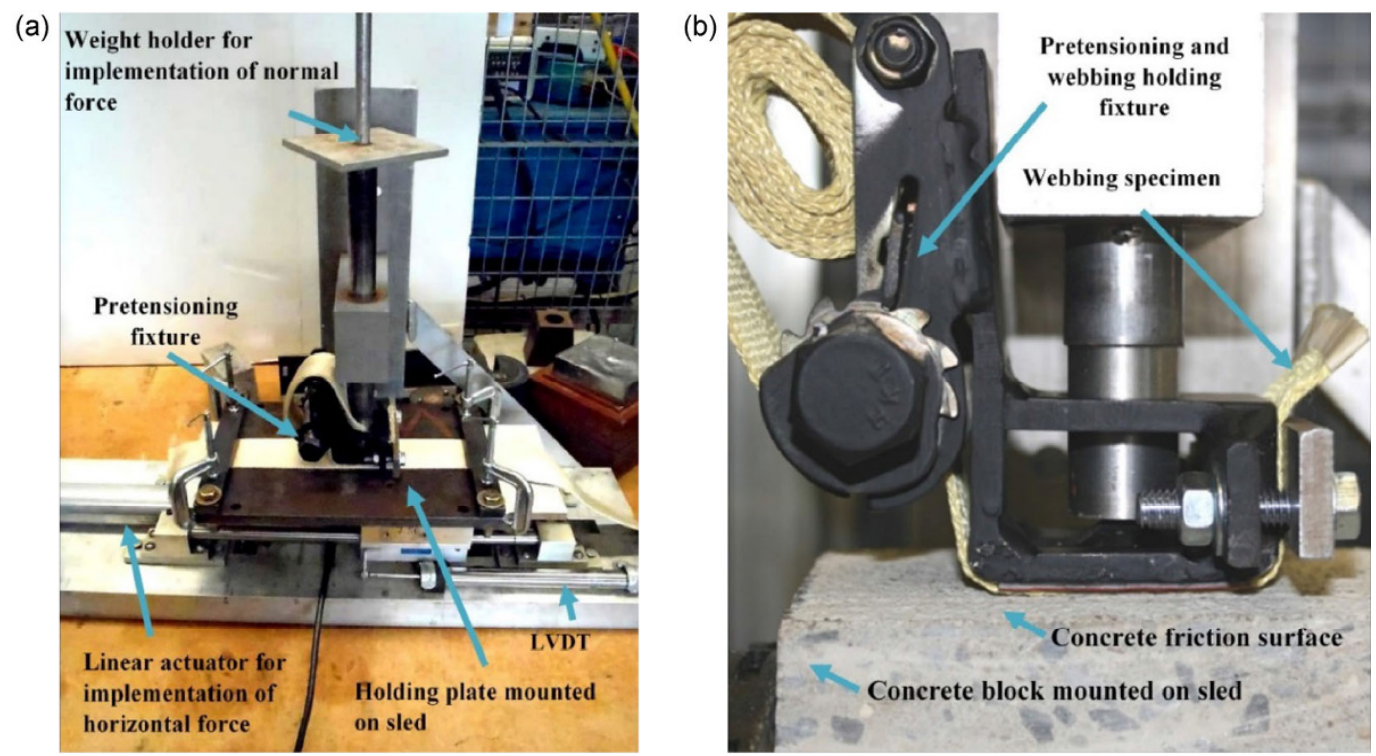

Fig. 4 (a) Overview of friction testing machine adapted for testing webbing specimens; (b) close-up view of the specimen during a friction test.

constant speed of $5 \mathrm{~mm} / \mathrm{s}$. An S-beam load cell was connected to the end of the actuator to measure the horizontal force acting on the sled. A linear variable differential transducer (LVDT) attached to the sled and the base of the testing apparatus measured the horizontal displacement of the sled. From the peak horizontal force required to initiate the movement of the sled $\left(F_{\text {sled }}\right)$ and the constant normal force $\left(F_{\text {normal }}\right)$, the static friction coefficient $\left(\mu_{\mathrm{s}}\right)$ was calculated using the classical friction equation:

$$
\mu_{S}=\frac{F_{\text {sled }}}{F_{\text {normal }}}
$$

Data from the tests was gathered using a graphic interface generated using LabVIEW, which plotted the applied force $\left(F_{\text {sled }}\right)$ measured from the S-beam load cell versus displacement $\left(\Delta_{\text {sled }}\right)$ of the sled measured by the LVDT. Friction tests were performed at room temperature and repeated at least five times for the different specimens and normal load configurations. Average, standard deviation, and coefficient of variation (CV) were calculated to account for the variability of the horizontal force measured during the tests.

\subsection{Test matrix}

The test matrix was defined based on conditions that could be present during the operation of the inflatable structure illustrated in Fig. 1. Friction tests at coupon level were divided into three sets. Set \#1 included stationary single-webbing specimens rubbing against smooth and rough concrete in dry and wet conditions. In this set, specimens were tested with the horizontal force applied parallel to the longitudinal direction of the webbing $\left(0^{\circ}\right)$. A normal force of $288 \mathrm{~N}$ was applied to a nominal contact area of $26 \mathrm{~cm}^{2}$. Set \#2 included stationary single-webbing specimens rubbing against a flat strip of the same webbing material as shown in Fig. 4(a). In this set, tests were also performed in dry and wet conditions; moreover, specimens were tested with the horizontal force parallel and perpendicular to the longitudinal direction of the webbing $\left(0^{\circ}\right.$ and $90^{\circ}$, respectively). The purpose of testing these two orientations was to evaluate the influence of the texture of the webbings on the friction coefficient. Tests were conducted under three loading scenarios with normal forces of $178 \mathrm{~N}, 356 \mathrm{~N}$, and $489 \mathrm{~N}$, applied to a contact area of $26 \mathrm{~cm}^{2}$. For Set \#3, a grid of four by three webbings was created to resemble a portion of the actual woven webbings used in the inflatable prototypes. In this set, specimens were rubbed against rough and smooth concrete surfaces in wet conditions. The specimens were tested at $0^{\circ}$ and $90^{\circ}$ with respect to the direction of application of the horizontal force. Table 1 summarizes the friction tests performed at coupon level. 
Table 1 Testing matrix for friction tests at coupon level.

\begin{tabular}{|c|c|c|c|c|c|}
\hline Set \# & Description & Code & Normal force $[\mathrm{N}]$ & $\begin{array}{c}\text { Contact area } \\
{\left[\mathrm{cm}^{2}\right]}\end{array}$ & $\begin{array}{l}\text { Number of } \\
\text { tests per } \\
\text { specimen }\end{array}$ \\
\hline \multirow{4}{*}{1} & Single webbing, rough concrete, dry & SW-RC-D & 288 & 26 & 5 \\
\hline & Single webbing, rough concrete, wet & SW-RC-W & 288 & 26 & 5 \\
\hline & Single webbing, smooth concrete, dry & SW-SC-D & 288 & 26 & 5 \\
\hline & Single webbing, smooth concrete, wet & SW-SC-W & 288 & 26 & 5 \\
\hline \multirow{4}{*}{2} & Single webbing on webbing, dry, $0^{\circ}$ & SWOW-D-0 & $178,356,489$ & 26 & 10 \\
\hline & Single webbing on webbing, dry, $90^{\circ}$ & SWOW-D-90 & $178,356,489$ & 26 & 10 \\
\hline & Single webbing on webbing, wet, $0^{\circ}$ & SWOW-W-0 & $178,356,489$ & 26 & 10 \\
\hline & Single webbing on webbing, wet, $90^{\circ}$ & SWOW-W-90 & $178,356,489$ & 26 & 10 \\
\hline \multirow{3}{*}{3} & Woven webbing, rough concrete, wet, $0^{\circ}$ & $\mathrm{WW}-\mathrm{RC}-\mathrm{W}-0^{\circ}$ & $178,356,489$ & 103 & 5 \\
\hline & Woven webbing, rough concrete, wet, $90^{\circ}$ & WW-RC-W-90 & $178,356,489$ & 103 & 5 \\
\hline & Woven webbing, smooth concrete, wet, $0^{\circ}$ & WW-SC-W-0 $0^{\circ}$ & $178,356,489$ & 103 & 10 \\
\hline
\end{tabular}

\subsection{Set \#1: Single webbing on concrete}

Friction coefficients for a single webbing rubbing against smooth concrete resulted in approximately 30 percent lower friction values than the friction values obtained for rough concrete. This difference is attributed to the smoothness of the concrete surface that contained considerably less surface irregularities where the webbing fibers could snag. For rough concrete dry conditions, the average friction coefficient was 0.52, while for wet conditions the average friction coefficient was 0.50 . For this surface, the tests demonstrated that despite the pre-tensioning applied to webbings prior to the execution of the friction tests, the fibers tended to snag on the irregularities of the rough surface. This effect is similar to the plowing effect described in Ref. [27], in which sharp asperities of the hard surface (concrete) can produce scratches or snagging when slid over a softer surface (webbing). For smooth concrete in dry conditions, the average friction coefficient was 0.35 , while for wet conditions the average friction coefficient resulted in a value of 0.37 . Specimens tested with this surface were practically intact since no snagging or abrasion was seen during the tests. The plowing effect, in addition to the low extensibility, of Vectran fibers [24] could have been the main reason for the difference in friction coefficients obtained for each type of concrete surface.

Test results also indicated that, for both types of surfaces, the wetting of the surfaces with water has little effect on the friction coefficient at coupon level. The difference in the values of friction coefficients is in the same order of magnitude as the variability of the horizontal force measured by the CV. However, the CVs were higher for smooth concrete, in the range of 12 to 22 percent, than for rough concrete for which the CVs ranged from 6 to 10 percent. Test results for Set $\# 1$ are summarized in Table 2.

\subsection{Set \#2: Single webbing on single webbing}

Similar to the results obtained for Set \#1, webbing surfaces in dry or wet conditions do not seem to affect the friction coefficient. Results for both conditions resulted in nearly identical values as summarized in Table 3. However, the orientation of the specimens produced a slight reduction of the friction coefficient for specimens tested with the fibers oriented perpendicularly to the direction of horizontal movement. That is, the difference in the friction coefficient between

Table 2 Summary of testing results for Set \#1.

\begin{tabular}{|c|c|c|c|c|c|}
\hline \multirow{2}{*}{$\begin{array}{l}\text { Specimen } \\
\text { code }\end{array}$} & \multicolumn{3}{|c|}{ Peak horizontal force } & \multirow{2}{*}{$\begin{array}{c}\text { Normal } \\
\text { force } \\
{[N]}\end{array}$} & \multirow{2}{*}{$\begin{array}{l}\text { Friction } \\
\text { coefficient }\end{array}$} \\
\hline & $\begin{array}{c}\text { Average } \\
{[\mathrm{N}]}\end{array}$ & $\begin{array}{c}\text { Std. Dev. } \\
{[\mathrm{N}]}\end{array}$ & $\begin{array}{l}\mathrm{CV} \\
{[\%]}\end{array}$ & & \\
\hline SW-RC-D & 148.66 & 9.12 & $6.13 \%$ & 288 & 0.52 \\
\hline SW-RC-W & 145.68 & 13.75 & $9.44 \%$ & 288 & 0.51 \\
\hline SW-SC-D & 101.06 & 22.51 & $22.27 \%$ & 288 & 0.35 \\
\hline SW-SC-W & 109.11 & 12.86 & $11.78 \%$ & 288 & 0.38 \\
\hline
\end{tabular}


Table 3 Summary of testing results for Set \#2.

\begin{tabular}{|c|c|c|c|c|c|c|}
\hline \multirow[b]{2}{*}{ Specimen Code } & \multirow[b]{2}{*}{$\begin{array}{c}\text { Normal Force } \\
{[\mathrm{N}]}\end{array}$} & \multicolumn{3}{|c|}{ Peak horizontal force } & \multirow[b]{2}{*}{$\begin{array}{l}\text { Individual friction } \\
\text { coefficient }\end{array}$} & \multirow[b]{2}{*}{$\begin{array}{c}\text { Global friction } \\
\text { coefficient }\end{array}$} \\
\hline & & $\begin{array}{l}\text { Average } \\
{[\mathrm{N}]}\end{array}$ & $\begin{array}{l}\text { Std. Dev. } \\
{[\mathrm{N}]}\end{array}$ & $\begin{array}{l}\mathrm{CV} \\
{[\%]}\end{array}$ & & \\
\hline \multirow{3}{*}{ SWOW-D-0 ${ }^{\circ}$} & 178 & 38.21 & 3.07 & 8.0 & 0.21 & \multirow{3}{*}{0.26} \\
\hline & 356 & 100.40 & 7.52 & 7.5 & 0.28 & \\
\hline & 489 & 126.82 & 8.85 & 7.0 & 0.26 & \\
\hline \multirow{3}{*}{ SWOW-D-90 } & 178 & 42.39 & 5.74 & 13.5 & 0.24 & \multirow{3}{*}{0.22} \\
\hline & 356 & 84.38 & 9.21 & 10.9 & 0.24 & \\
\hline & 489 & 106.76 & 8.85 & 8.3 & 0.22 & \\
\hline \multirow{3}{*}{ SWOW-W-0 ${ }^{\circ}$} & 178 & 37.50 & 2.09 & 5.6 & 0.21 & \multirow{3}{*}{0.26} \\
\hline & 356 & 94.97 & 10.36 & 10.9 & 0.27 & \\
\hline & 489 & 131.44 & 4.80 & 3.7 & 0.27 & \\
\hline \multirow{3}{*}{ SWOW-W-90 } & 178 & 43.41 & 4.63 & 10.7 & 0.24 & \multirow{3}{*}{0.23} \\
\hline & 356 & 75.62 & 5.52 & 7.3 & 0.21 & \\
\hline & 489 & 114.85 & 10.54 & 9.2 & 0.23 & \\
\hline
\end{tabular}

specimens tested at $0^{\circ}(0.26)$ versus specimens tested at $90^{\circ}(0.23)$ was 13 percent. This percentage is similar to the variability of the horizontal forces measured during the tests, as seen in the CVs summarized in Table 3, which ranged from 3.5 to 13.5 percent.

Table 3 summarizes results for the three levels of normal load that were used in this set of tests. The global friction coefficient for each testing configuration, dry or wet, $0^{\circ}$ or $90^{\circ}$ (illustrated in Fig. 5), was determined by comparing the average horizontal force to the applied normal load and then by determining the slope of the linear fitting of the data points. This method produced values of friction coefficients with a maximum difference of \pm 6 percent when compared to the average of the three tests at each load level. An example of test data used to determine the global friction coefficient is illustrated in Fig. 6.

This set of tests with single webbing rubbing against another individual webbing can be seen as an initial effort for evaluation of the internal friction of the woven webbings, in which the relatively low friction coefficients obtained from the tests (typically around 0.2 ) are attributed to the silky texture of the webbings. These results are useful for understanding first, how the macro-fabric of the external layer of the inflatable structure shown in Fig. 1 will behave during the unfolding process expected during the deployment sequence, and second, if the macro-fabric will be prone to the formation and elimination of wrinkles when subjected to the pressurization in a confined environment.
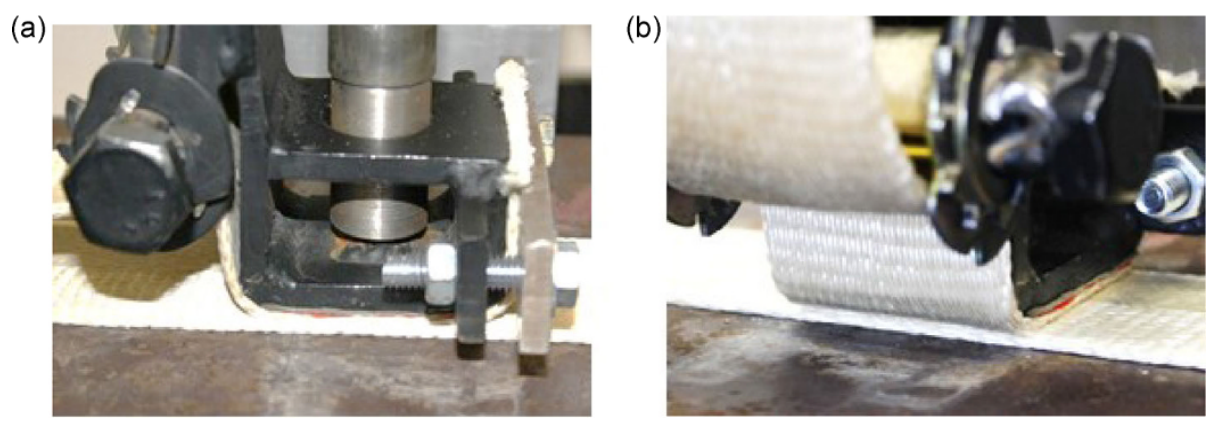

Fig. 5 Specimen orientation with respect to the horizontal sliding: (a) Webbing on webbing, $0^{\circ}$; (b) Webbing on webbing, $90^{\circ}$. 


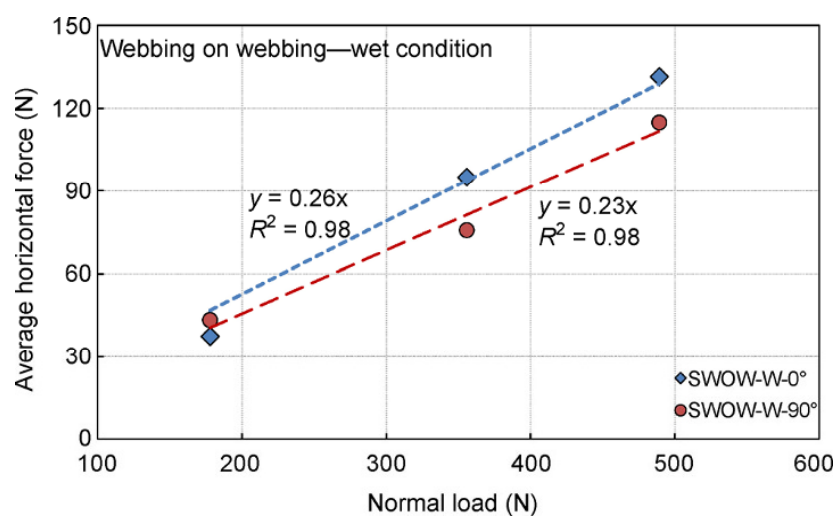

Fig. 6 Plot of average horizontal force versus normal load under wet conditions.

\subsection{Set \#3: Woven webbings on concrete}

\subsubsection{Test setup and specimen preparation}

Friction tests on specimens of woven webbings were performed in order to estimate the friction coefficient using a more realistic specimen than a single webbing. The specimen of woven webbings consisted of a matrix of three by four webbings, with each one pretensioned with $260 \mathrm{~N} / \mathrm{mm}$ and attached to a steel holding frame using steel side bars secured with bolts to maintain the tension on the webbings, as illustrated in Fig. 7. This set of tests was run in the same fashion as the single-webbing friction tests, except that the surface of the concrete block was stationary, while the specimen of woven webbings slid horizontally underneath the concrete surface. Concrete blocks were held stationary by using a holding cup that allowed the concrete block to stay firmly in place during testing, while transferring the normal load from above. The leading edges of the concrete blocks were chamfered to prevent snagging during the horizontal movement of the woven webbings. The effective contact area of the concrete block was $103 \mathrm{~cm}^{2}$, which assured that at least two webbings in each direction were in contact with the concrete surface. Figure 7 illustrates the test setup for this series of friction tests.

Specimens of woven webbings were evaluated under three scenarios, all in wet conditions. The first scenario tested a specimen rubbing against a rough concrete surface with the groves of the contact surface parallel to the direction of travel of the woven webbings $\left(0^{\circ}\right)$. The second scenario tested a specimen rubbing against a rough concrete surface with the

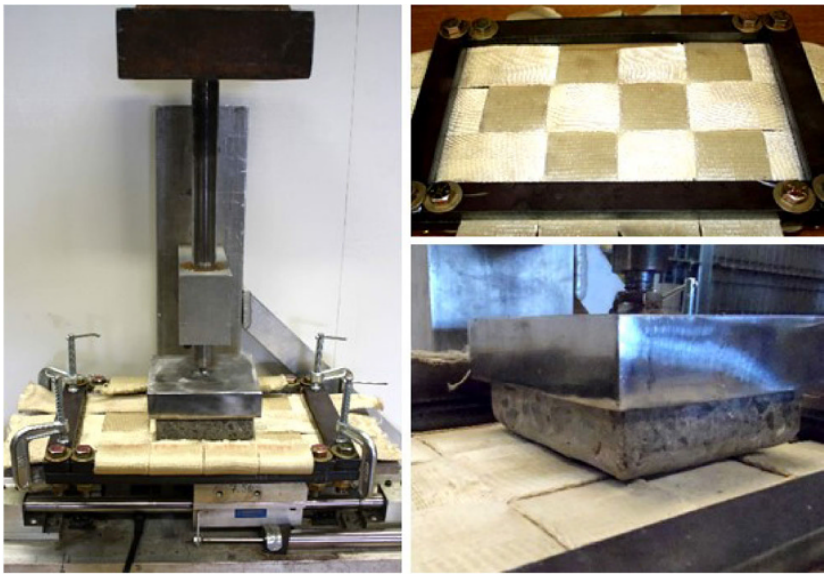

Fig. 7 Test setup overview (left); specimen of woven webbings (right, top); close-up view of contact between concrete block and woven webbings (right, bottom).

grooves of the contact surface perpendicular to the direction of travel $\left(90^{\circ}\right)$. The third scenario tested a specimen rubbing against a smooth concrete surface with the concrete block oriented at $0^{\circ}$. Tests were run using normal loads of $178 \mathrm{~N}, 356 \mathrm{~N}$ and $489 \mathrm{~N}$ applied on a nominal area of $103 \mathrm{~cm}^{2}$, which produced normal pressures of $17 \mathrm{kPa}, 34 \mathrm{kPa}$ and $48 \mathrm{kPa}$, respectively. Limitations on the capacity of the testing machine for this testing configuration did not allow tests at higher normal pressures.

\subsubsection{Test results}

Test results corresponding to Set \#3 are summarized in Table 4. Similar to the Set $\# 2$ test results, the global friction coefficient for each test configuration of Set \#3 was found by comparing the average horizontal force to the applied normal load and by determining the slope of the linear fitting of the test data. Similar to results from Set \#2, the slope of the linear fitting predicted slightly lower values than the individual averages calculated for each level of normal load. The maximum computed difference was 5 percent. Test results for rough concrete show that for the $0^{\circ}$ orientation and the $90^{\circ}$ orientation the friction coefficients were 0.87 and 0.86 respectively. Changing from a rough to smooth concrete surface reduced the friction coefficient from 0.86 to 0.72 (nearly 19 percent lower).

Comparing test results obtained for Set \#3 (Table 4) with results obtained for Set \#1 (Table 2), the friction coefficients increased in the range of 72 to 95 percent for specimens rubbing the same type of concrete surface 
Table 4 Summary of testing results for Set \#3.

\begin{tabular}{|c|c|c|c|c|c|c|}
\hline \multirow[b]{2}{*}{ Specimen code } & \multirow{2}{*}{$\begin{array}{l}\text { Normal Load } \\
{[\mathrm{N}]}\end{array}$} & \multicolumn{3}{|c|}{ Peak horizontal force } & \multirow{2}{*}{$\begin{array}{l}\text { Individual } \\
\text { friction } \\
\text { coefficient }\end{array}$} & \multirow{2}{*}{$\begin{array}{l}\text { Global } \\
\text { friction coefficient }\end{array}$} \\
\hline & & $\begin{array}{l}\text { Average } \\
{[\mathrm{N}]}\end{array}$ & $\begin{array}{l}\text { Std. Dev. } \\
{[\mathrm{N}]}\end{array}$ & $\begin{array}{l}\mathrm{CV} \\
{[\%]}\end{array}$ & & \\
\hline \multirow{3}{*}{ WW-RC-W- $0^{\circ}$} & 178 & 155.55 & 14.50 & 9.30 & 0.87 & \multirow{3}{*}{0.87} \\
\hline & 356 & 346.34 & 32.47 & 9.40 & 0.97 & \\
\hline & 489 & 398.16 & 39.46 & 9.90 & 0.81 & \\
\hline \multirow{3}{*}{ WW-RC-W-90 } & 178 & 141.54 & 8.01 & 5.70 & 0.80 & \multirow{3}{*}{0.86} \\
\hline & 356 & 332.06 & 57.07 & 17.20 & 0.93 & \\
\hline & 489 & 417.73 & 47.91 & 11.50 & 0.85 & \\
\hline \multirow{3}{*}{ WW-SC-W- $0^{\circ}$} & 178 & 144.92 & 4.23 & 2.90 & 0.81 & \multirow{3}{*}{0.72} \\
\hline & 356 & 286.20 & 39.01 & 13.60 & 0.80 & \\
\hline & 489 & 324.94 & 34.07 & 10.50 & 0.66 & \\
\hline
\end{tabular}

and surface condition. This significant overestimation in the values of the friction coefficients of specimens of woven webbings is attributed to the following factors: (a) The raised edges of webbings that form the weave pattern created additional places where the grooves of the rough concrete surface could catch and, therefore, increased the chances for snagging individual fibers; (b) the test configuration used for this set of experiments with specimens of woven webbings may have influenced the results. An alternative testing configuration would be returning to a stationary smaller specimen of woven webbings rubbing against a larger movable concrete surface. This alternative configuration would eliminate the possibility of snagging, but it would also require modifications of the friction testing machine used in this set of tests that were beyond the scope of the evaluations at coupon level.

A summary of all testing results obtained from experiments at coupon level is illustrated in the chart of Fig. 8. In this chart, results for sets $\# 1, \# 2$, and $\# 3$ are grouped by increasing values of friction coefficient. Bars placed on each column of the chart are a graphical representation of the variability of data. The magnitude of the bar indicates the average $\mathrm{CV}$ calculated from data presented in Tables 2,3, and 4. Set \#1 (single webbings on concrete) displayed high variability with $\mathrm{CV}$ values ranging from 6.1 percent to a maximum of 22.6 percent. For Set \#2 (single webbing on single webbing), the averaged variability resulted in a value of 8.6 percent, while for Set \#3 (woven webbing on concrete) the average variability resulted in a value of 10 percent.

Looking at the results summarized in Fig. 8, it is apparent that there is a size effect in the experimental determination of the friction coefficient at coupon level. For the same type of concrete surface, test results indicate that as the size of the testing specimen increases, from single webbing to woven webbings, the friction coefficient increases as well. One of the factors that may be influencing in the tests results is the contact area of the webbing specimens with the concrete surface, and the size of the specimen determines the extent of contact area. Although the actual contact area was not measured during this set of tests, the nominal contact area summarized in Table 1 provides an indication of the increase of the contact area as the size of the testing specimen increased. These results seem to be consistent with observations made by Gupta [21] and by El-Mogahzy and Gupta [28] for the evaluation of friction behavior of fibrous materials used in textiles. They identified the mode of contact (point, line, or area, which are related to the size of the tests) as one of the factors playing a role in friction. They pointed out that the larger the area of contact the larger would be the value of the friction coefficient.

A possible effect of specimen orientation in the coefficient of friction can be seen in two sets of testing specimens at coupon level. The first set corresponds 


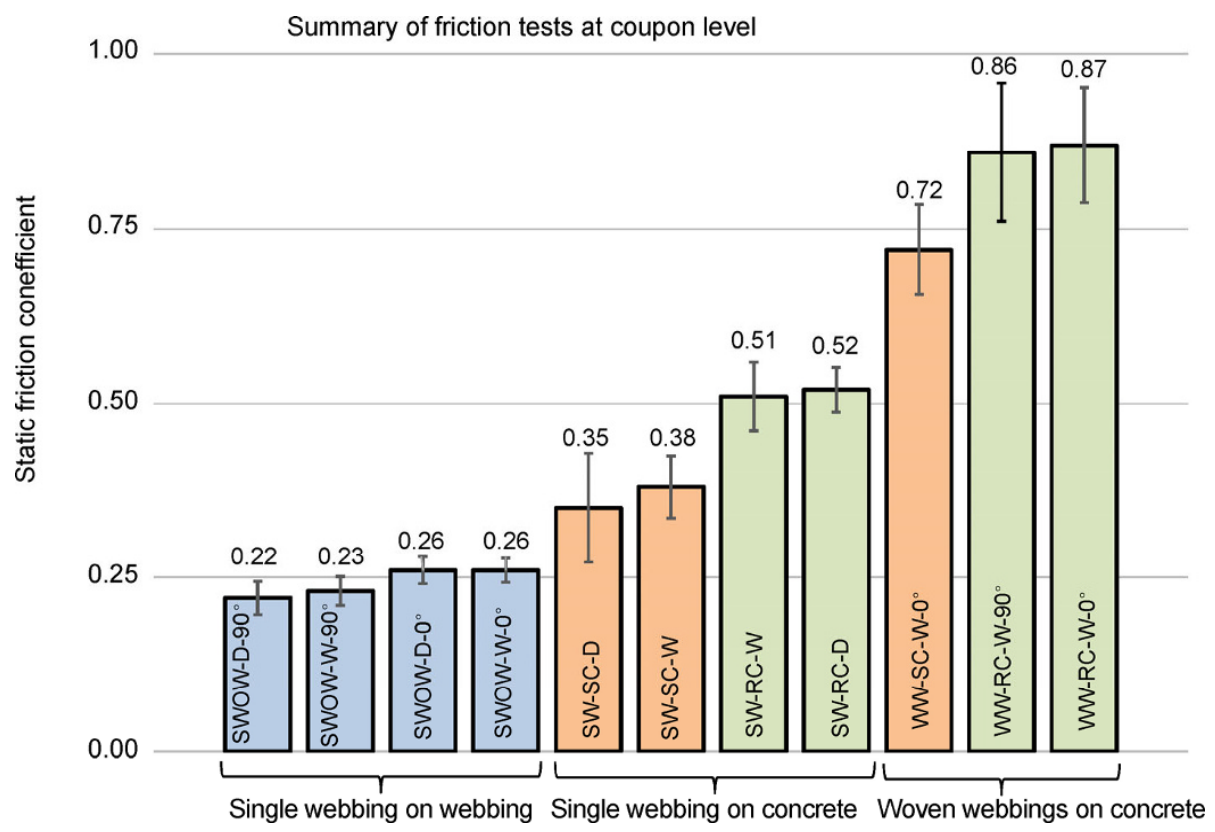

Fig. 8 Summary of friction tests at coupon level.

to specimens of single webbing rubbing over another single dry or wet single webbing. The second set corresponds to specimens of woven webbings rubbing over wet rough concrete. The first set is identified with codes SWOW- $0^{\circ}$ and SWOW- $90^{\circ}$ in both dry and dry conditions. The second set is identified with codes WW-RC-W- $0^{\circ}$ and WW-RC-W- $90^{\circ}$ as summarized in Table 1 and the summary of testing results of Fig. 8.

Comparing friction coefficients of both sets it is clear that the orientation effects are more evident in the specimens of single webbings than in the specimens of woven webbings as illustrated in Fig. 8.

For the first set, the friction coefficient for the $0^{\circ}$ orientation was 0.03 to 0.04 (or $+13 \%$ to $+18 \%$, for wet and dry conditions, respectively) higher than values obtained for the $90^{\circ}$ orientation. The difference can be explained in terms of the actual contact between specimens for both orientations (see Fig. 5 as a reference). Considering dry conditions, for $0^{\circ}$ orientation, the longitudinal fibers of the sliding specimen are aligned with the longitudinal fibers of the fixed specimen. It can be argued that the alignment of fibers along the same direction for both specimens, maximizes the area of contact between individual fibers and is reflected in a higher coefficient of friction. On the contrary, for the $90^{\circ}$ orientation, the longitudinal fibers of the sliding specimen are perpendicular to the longitudinal fibers of the fixed specimen. It can be argued that this configuration reduces the actual area of contact of individual fibers to the area where fibers intersect each other, leading to a lower coefficient of friction.

The observations derived from this set of experiments are consistent with observations made by Gupta [21] and by Allaoui et al. [29]. The latest studied the influence of dry woven fabrics mesostructure on fabric-fabric contact behavior and concluded that the friction response is very sensitive to the relative positioning and orientation of the specimens.

For the second set, the orientation of the woven webbing specimens rubbing over wet rough concrete does not affect the friction response. In this set, the friction coefficient for the $0^{\circ}$ orientation was just 0.01 (or $+1 \%$ ) higher than values obtained for the $90^{\circ}$ orientation. However, this result may have been influenced by the testing configuration in which the concrete surface was fixed, and the woven webbing slid underneath the concrete block as illustrated in Fig. 7. From an application point of view, it is convenient to see that the woven webbing is independent of sliding orientation because the membrane can take virtually any position when the inflatable plug is deployed and positioned within the confining walls of the tunnel segment [11, 12]. 
Results summarized in Fig. 8 also show that friction coefficient obtained from specimens in contact with concrete surfaces in a soaking-wet environment were nearly identical to friction values obtained for dry conditions. The only specimens that show some difference are single webbings rubbing over smooth concrete. For this particular case the small difference (less than $10 \%$ in the friction coefficient) can be attributed to the hydrophobicity of synthetic fibers like Vectran, that is, they do not absorb water. The effect of wetting is the result of penetration of water through the interstitial space between fibers and yarns that constitute the webbing itself. The penetration of interstitial water caused the yarns to separate each other to some extent resulting in an increase of the area of contact and, thus, in a slight increase of the friction coefficient. This effect is not observed in the other specimens such as a single or woven webbings, rubbing over rough concrete. In this set of tests, it can be argued that the frictional behavior was influenced by two factors. First, the channeling effect the asperities of the rough concrete surface and second, the mechanical application of the normal load. The combination of both factors may have squeezed the water out of the contact zone and reduced its influence in the frictional behavior that resulted in lower coefficients of friction.

\section{Friction tests at system level}

\subsection{Reduced-scale prototype: Materials and geometry}

The friction characteristics at system level were evaluated using confined inflatable prototype manufactured and tested at a reduced scale. The reduced scale was selected based on a tradeoff of the following factors. (1) The accessibility to precast concrete pipes commercially available that wouldn't require special preparation other than the installation of the end-cap, along with accessories for mounting of instrumentation, and with the same inner surface finish that was evaluated in the coupon tests. Upon extensive search of readily available products, it was determined that a prestressed, precast concrete pipe having one-quarter of the dimensions of the actual full-scale subway tunnel model would satisfy those basic prerequisites.

(2) The other reason for selecting the present scale was related to the characteristics of the membrane of the inflatable plug. In terms of manufacturing, a quarter-scale prototype was considered the smallest scale that could be implemented with all the features of the full-scale prototype that was manufactured and tested afterwards. That is, the quarter scale model was made for both the experimental tests reported herein and for the manufacturing requirements for the supplier since this was the first prototype of this design. Some of these features included the interlayer connection in the three-layer system illustrated in Fig. 2, the transition of woven webbings from the cylindrical portion to the spherical end-caps, the integration of inflation and pressurization ports, among others. (3) The third factor taken into account for selection of the present scale was the handling of the reduced-scale prototype. Since several repetitions were expected during the execution of the experiments, a quarter-scale model would allow a significant larger number of tests than the full-scale model would allow. For instance, multiple tests of the reducedscale model could be conducted in a day whereas the full-scale model required multiple days to conduct a single test. This scale allowed examination of specific design parameters in a repeatable testing environment in a condensed time frame.

As in the full-scale prototype shown in Fig. 1, the geometric design of the reduced-scale prototype consisted of a combination of a cylinder with two hemispherical end caps. The cylinder used for this testing had a diameter of 1.24 meters and a length of 1.14 meters. The length of the cylindrical part was determined using the method outlined in Ref. [1]. The friction coefficient used to determine the cylindrical length was the lowest value obtained from tests at coupon level for a single webbing rubbing against smooth concrete. A friction coefficient of 0.35 with a variability of \pm 22 percent led to a value of 0.27 , which was adopted for the computations. The reasoning behind the selection of this value was based on the following observations: (a) Experimental values obtained from tests using single webbings or small specimens of woven webbings showed increasing values of friction coefficients as the scale of the test increased, as illustrated in Fig. 8. However, this increasing tendency may have been an overestimation influenced by the test configuration in which the 
mechanical pressure applied at coupon level produces different effects than the fluid pressure expected to be applied at system level; (b) moreover, the presence of edges on the friction surface, as well as the presence of snagging seen on the specimens of woven webbings, may have contributed to an overestimation of the friction coefficient. These observations led to the adoption of the minimum value obtained at coupon level, putting the design on the conservative side.

The cylindrical part was capped by two hemispherical end caps with a diameter of 1.24 meters. These end-caps included two partitions delimited by ropes created for manufacturing reasons for gradual termination of longitudinal webbings, as shown in Fig. 9(a). This construction was selected by the manufacturer in order to avoid the overcrowding of Vectran webbing at the apex of each hemisphere [23]. An aluminum fitting was built in to the plug to function as an air- or water-filling port, and another fitting was built in to function as an air release port; both ports were integrated to the webbed structure on the surface of one of the hemispherical end-caps. Figure 9 shows the reduced-scale prototype during preparation for the tests.

\subsection{Reduced-scale test setup}

A schematic representation of the test setup built for experimentation at reduced-scale is shown in Fig. 10. In this schematic, the confining environment representative of a tunnel segment is simulated by a pipe (also referred to as a tunnel) made of prestressed, precast concrete (1). This pipe is 6 meters long with an internal diameter of 1.22 meters, and it is capable of containing a maximum fluid pressurization of $621 \mathrm{kPag}$. The pipe is closed in one end with a bulkhead capable of containing a maximum fluid pressurization of $414 \mathrm{kPag}$ (2). The inner surface of the pipe has a surface finish qualified as ICRI-CSP \#1 (smooth concrete) [25]. During the tests, the pipe was filled and pressurized with the water stored in a tank (3), using two different pumps: One provided a high flow at low pressure needed for filling the pipe relatively quickly (4); the second pump provided a low flow at high pressure needed for pressurization of the water contained within the pipe (5). The reduced-scale plug was inflated first with air at low pressure and then filled with water using a high-flow pump (6). Once tests were completed, the pipe and the plug were drained using a smaller high-flow pump (7). Leaking water was captured in a collection tank placed at the open end of the pipe (8). The sensing system was configured to measure the following variables: (a) The internal pressure of the inflatable and the external pressure applied by the water pushing the plug; these two pressures were measured with pressure transducers connected to the inflatable air release fittings and pressure transducers located in the pipe bulkhead; (b) the action of the pressures produced longitudinal with an array of lasers placed in the open end of the pipe. All tests were recorded with cameras located inside the pipe at both ends: one in the dry end of the inflatable plug and one submerged in the flooded end.

\subsection{Test procedure for slippage tests}

Initially, the inflatable plug was placed into the tunnel in the deflated position and manually aligned with the longitudinal axis of the tunnel. Once connected to the inflation system, the plug was inflated with air at a pressure of $2 \mathrm{kPag}$ to complete the initial positioning. Then, the air was gradually replaced by water and
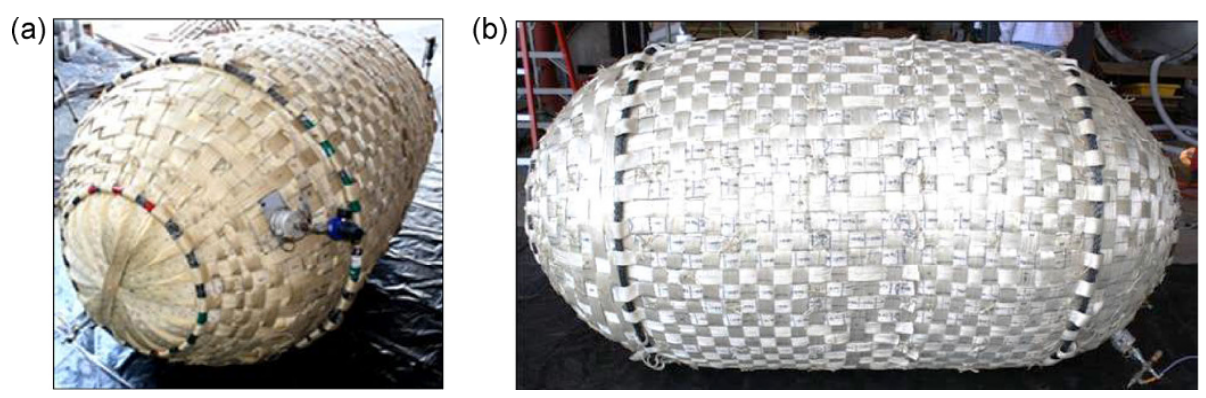

Fig. 9 Reduced-scale prototype used for evaluation of the friction coefficient at system level: (a) Hemispherical end-cap with fill port; (b) cylindrical part. 


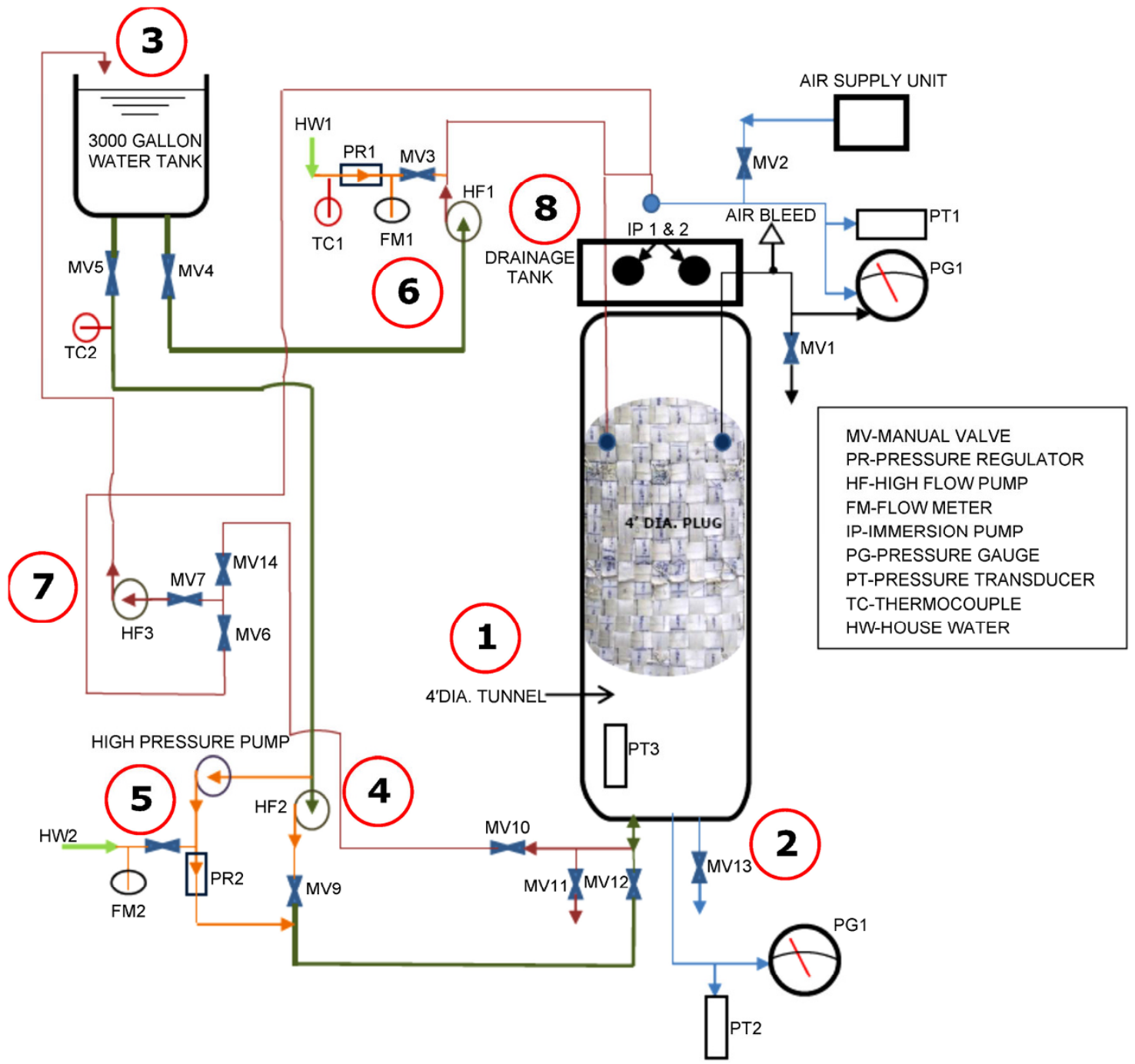

Fig. 10 Schematic of test setup for slippage tests at reduced scale.

pressurized to $34 \mathrm{kPag}$. After the plug was completely filled and partially pressurized, the tunnel was filled with water but not pressurized. This initial procedure allowed the stabilization of the test setup as well as initialization of the data acquisition system. Plug pressure, tunnel pressure, and plug horizontal displacement were collected at a frequency of $1 \mathrm{~Hz}$. Figure 11 shows the sequences of initial air inflation of the plug and the tunnel filling process. The test configuration after these initial steps and previous to the beginning of the slippage tests is illustrated in Fig. 12.

The main goal of this set of tests was to find the combination of pressures at which the plug would move due to the tunnel pressure acting on the hemispherical end-cap exposed to flooding. Because all pressure regulators and switches were manually operated, at least two people were required for the execution of the tests. One person controlled the plug pressure while the other controlled the tunnel pressure. Changing the tunnel pressure had a residual effect on the plug pressure. That is, when the tunnel pressure was increased or decreased, it produced an increase or decrease of the plug pressure, respectively. This behavior was due to the confining effect of the tunnel and the incompressibility of water that required continuous regulation of the pressures to maintain them at the selected values. Three pressure scenarios were selected for inducing slippage of the plug. For all test configurations, a loud thumping noise occurred when slippage took place; this was also an indication that the test could be stopped. 


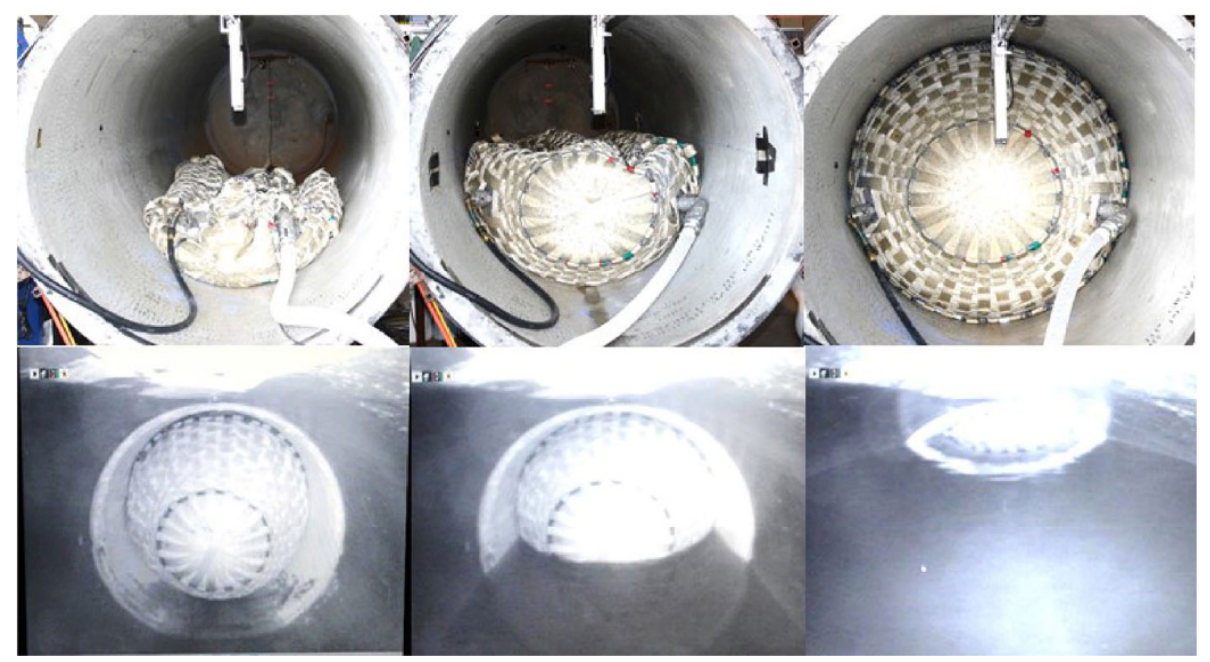

Fig. 11 Plug air inflation (top) and tunnel water filling (bottom) sequences for reduced-scale tests.

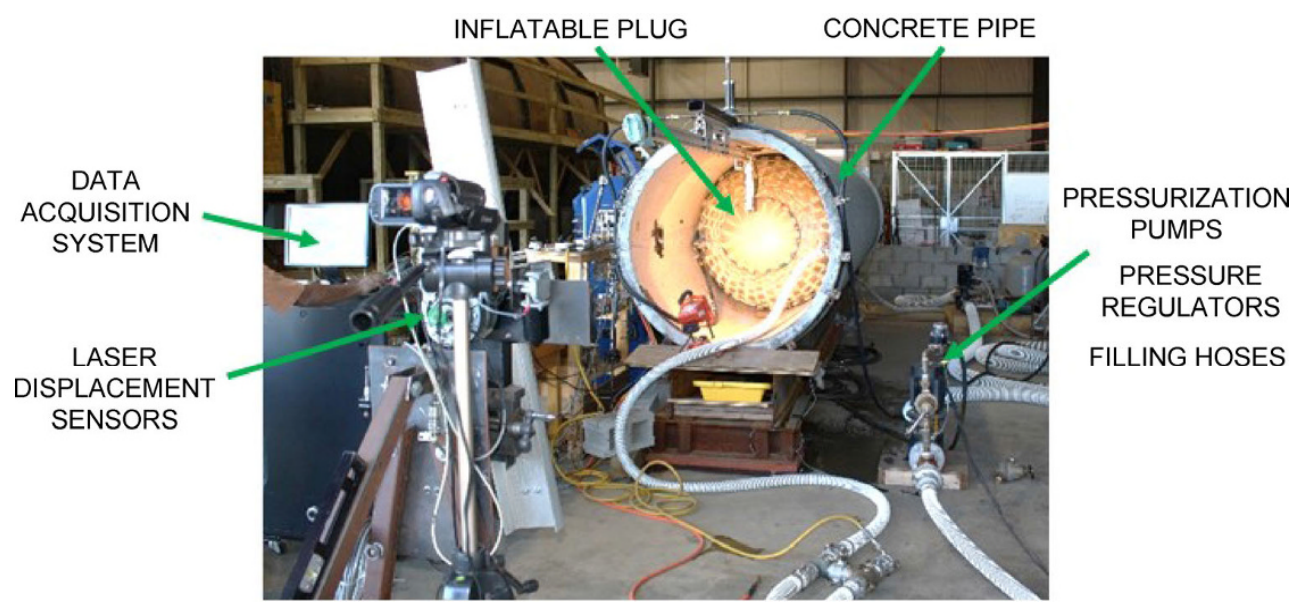

Fig. 12 Overview of test setup during slippage tests at reduced scale.

The tests began at the lowest plug pressure and continued to the next highest pressure systematically. When testing for one pressure was completed, collected data was saved and a new file was created in the data acquisition system for the next pressure level. When all selected plug and tunnel pressures were recorded for a given pressure scenario, the plug and tunnel were depressurized, the plug removed from the tunnel and allowed to air dry before testing the next pressurization scenario.

\subsection{Evaluation of slippage: Testing scenarios}

Ideally, to ensure that the plug system works properly once it has been deployed and that it conforms to the shape of the tunnel, the internal (or plug) pressure should always be greater than the external (or tunnel) pressure $\left(p_{\mathrm{i}}>p_{\mathrm{e}}\right)$ in order to maintain the stability of the inflatable. However, there can be two main scenarios for which the two pressures could equalize and therefore compromise the stability of the system:

A. The first scenario assumes that there is an increase in the external pressure $\left(p_{\mathrm{e}}\right)$ in which its magnitude gradually approaches the internal pressure $\left(p_{\mathrm{i}}\right)$. Under this scenario, two possible conditions are considered:

1. Once the rise of the external pressure has been detected, the plug pressure goes up but only to a certain extent dictated by the capacity of the pressurizing system and the factor of safety of the weakest structural component of the inflatable. Typically, a pressure relief device installed in the plug pressurization system 
would prevent over-pressurization of the plug, maintaining its internal pressure approximately constant while the external pressure continues rising. Eventually, the magnitude of the two pressures will converge to the same magnitude and the plug will slip. The holding capacity of the inflatable plug will be dictated by the friction coefficient of the system. This scenario was tested, and it was identified as sequence A-1.

2. Once the rise of the external pressure has been detected, the plug pressurization system does not include (or does not function properly) a pressure relief device and the plug pressure increases, accompanying the increase of external pressure. Here again, the magnitude of the two pressures will eventually converge to the same value and the plug will slip. Here too, the holding capacity of the inflatable plug will be dictated by the friction coefficient of the system. This scenario was tested, and it was identified as sequence A-2.

B. The second scenario assumes a decrease in the plug pressure while the tunnel pressure remains constant. The decrease of plug pressure can be attributed to a leak in the membrane originated by a puncture on the plug or due to a failure of the pressurizing system in maintaining the selected pressure. As in the previous scenarios, the magnitude of the two pressures will converge to the same value and, eventually, the plug will slip. The holding capacity of the inflatable plug will be dictated by the friction coefficient of the system. This scenario was tested, and it was identified as sequence $B$.

These scenarios were tested at least three times for different pressure levels in order to analyze the influence of the magnitude of the pressures used for the tests. Table 5 summarizes the combinations of pressures used for each scenario.

\subsection{Test results and discussion}

\subsubsection{Sequence A-1}

In this set of tests, the tunnel pressure was gradually increased at a rate in the range of 0.28 to $0.41 \mathrm{kPag}$ per second. As expected, during the increase of the
Table 5 Pressurization sequences for slippage tests at a reduced scale.

\begin{tabular}{|c|c|c|c|}
\hline Sequence A-1 & Level & $\begin{array}{l}\text { Plug pressure } \\
\qquad p_{\mathrm{i}}[\mathrm{kPag}]\end{array}$ & $\begin{array}{c}\text { External pressure } \\
\qquad p_{\mathrm{e}}[\mathrm{kPag}] \\
\text { Initial } \rightarrow \text { target }\end{array}$ \\
\hline \multirow{3}{*}{$\begin{array}{l}p_{\mathrm{i}} \text { constant } \\
p_{\mathrm{e}} \text { increasing }\end{array}$} & 1 & $207 *$ & $138 \rightarrow 207$ \\
\hline & 2 & $276^{*}$ & $207 \rightarrow 276$ \\
\hline & 3 & $345^{*}$ & $207 \rightarrow 345$ \\
\hline Sequence A-2 & Level & $\begin{array}{l}\text { Plug pressure } \\
\qquad p_{\mathrm{i}}[\mathrm{kPag}]\end{array}$ & $\begin{array}{c}\text { External pressure } \\
\qquad p_{\mathrm{e}}[\mathrm{kPag}] \\
\text { Initial } \rightarrow \text { Target }\end{array}$ \\
\hline$p_{\mathrm{i}}$ initially & 1 & $138^{\#}$ & $69 \rightarrow 138$ \\
\hline constant & 2 & $207^{\#}$ & $138 \rightarrow 207$ \\
\hline$p_{\mathrm{e}}$ increasing & 3 & $276^{\#}$ & $172 \rightarrow 276$ \\
\hline Sequence B & Level & $\begin{array}{c}\text { Plug pressure } \\
\qquad p_{\mathrm{i}}[\mathrm{kPag}] \\
\text { Initial } \rightarrow \text { Target }\end{array}$ & $\begin{array}{c}\text { External pressure } \\
p_{\mathrm{e}}[\mathrm{kPag}]\end{array}$ \\
\hline $\begin{array}{l}p_{\mathrm{i}} \text { decreasing } \\
p_{\mathrm{e}} \text { constant }\end{array}$ & $\begin{array}{l}1 \\
2 \\
3\end{array}$ & $\begin{aligned} 379 & \rightarrow 276 \\
276 & \rightarrow 207 \\
207 & \rightarrow 138\end{aligned}$ & $\begin{array}{l}276 \\
207 \\
138\end{array}$ \\
\hline
\end{tabular}

*Pressure $p_{\mathrm{i}}$ maintained constant during the increase of $p_{\mathrm{e}}$

${ }^{*}$ Pressure $p_{\mathrm{i}}$ not controlled during the increase of $p_{\mathrm{e}}$

tunnel pressure, the plug pressure had a tendency to increase too, but it was kept constant by releasing water through the air release port installed in the inflatable plug. The plug pressure was kept close to the target value until slippage was sensed. Slippage of the plug in the tunnel was accompanied by a series of loud popping noises. The first popping sound indicated the onset of slippage, which indicated the overcoming of the static friction. The occurrence of noise in frictional systems is not unusual and has been studied for decades [20]. The mechanism responsible for the sound production derives from the interface itself. At microscopic level, surfaces are not perfectly flat and typically contain numerous asperities whose size is of order of micrometers or even smaller. During the sliding, asperities of one surface hit asperities of the antagonist surface and all these micro-impacts generate vibration of the solids which, in turn, produces sound [30,31]. Depending on the contact pressure, friction noises can be classified 
in two types: (a) When the contact pressure is high, the contact is strong. The friction noise originates from mechanical instabilities in the contact such as stickslip. The sound is produced by the vibrational response of the coupled solids. The sound pressure level is high and the sound is confined to a narrow frequency band with few dominant frequencies; (b) when the contact pressure is low, the contact is weak and the sliding produces low noise represented by a wide range of frequencies; it is known as "roughness noise" [30]. Although noise sensors were not installed in the reduced-scale testing system, the thumping noises heard during the experiments seemed to be closer to the first type of friction noise in which the sound was originated by the sliding of two solid surfaces (concrete and highly tensioned webbings) subjected to a relatively strong contact originated by pressurization of the inflatable.

Immediately after slippage, there was a tendency of the tunnel pressure to drop sharply right after the first popping sound, as illustrated in the pressure data plotted in Fig. 13. This decrease of pressure was attributed to the bulk movement of the plug and the resulting increase in the volume of the cavity behind the plug.

To understand the horizontal movement at slippage, the tunnel pressure (after the first slip) was maintained as close to a constant value as possible until a steady set of popping noises were heard. The horizontal movement of the plug was detected by the laser displacement sensors and these readings showed a clear and relatively quick increase in the magnitude of the horizontal displacement when the plug slipped. An example of pressures and displacements collected for sequence A-1 is illustrated in Fig. 13. From this graph, it can be seen that the plug slipped once the friction was overcome. The four lasers installed for measuring displacement of the different points on the surface of the dry hemispherical end-cap started recording displacements almost simultaneously. In Fig. 13, the difference in the amplitude of the laser readings after the slippage of the plug is due to the position of the lasers. Laser LB was located at the tip of the hemispherical cap and registered the maximum horizontal displacement (about $11 \mathrm{~mm}$ ). Laser L1 measured horizontal displacements of a point on the
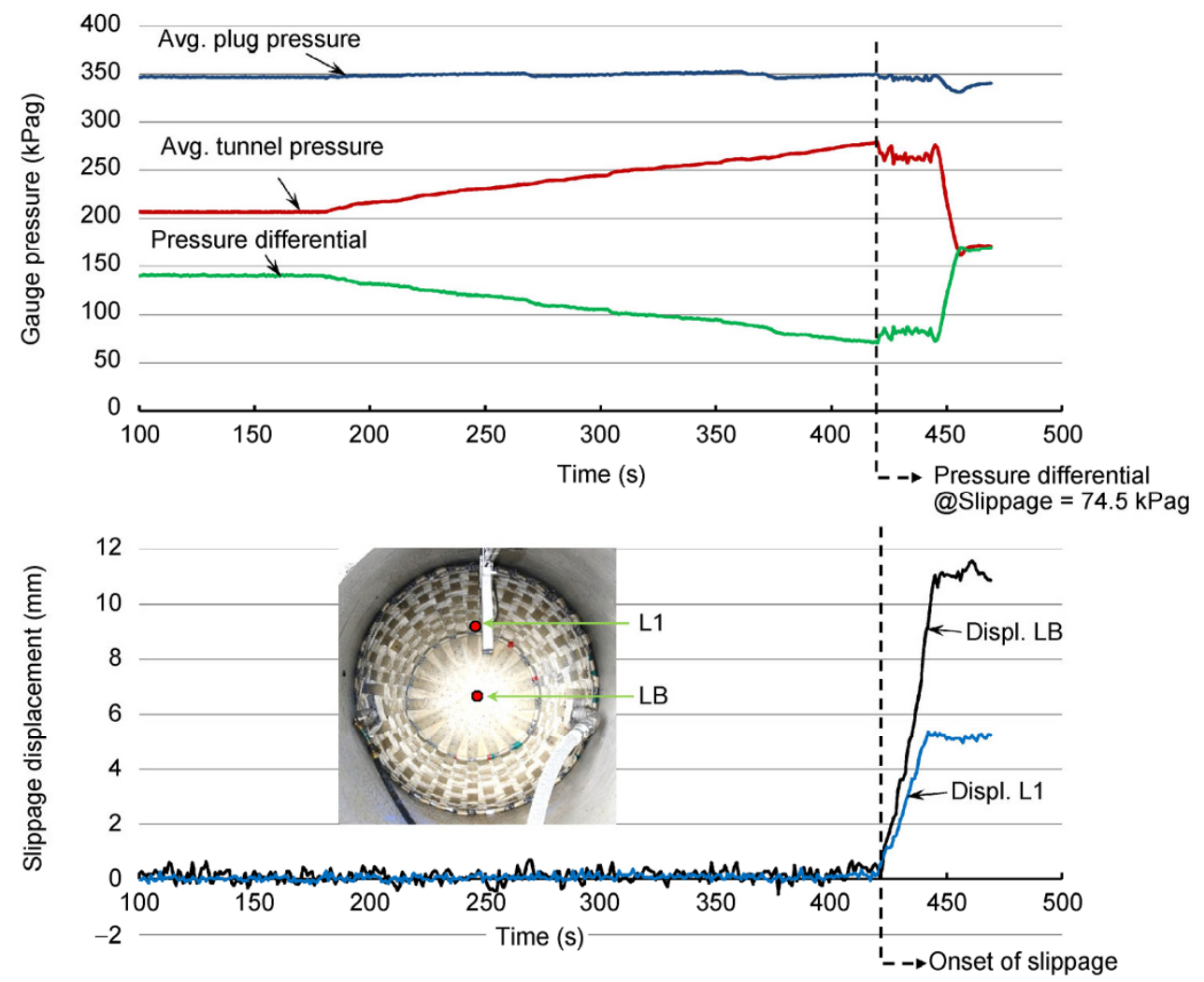

Fig. 13 Slippage tests: Sequence A-1, Test \#3, and tunnel pressure level 3. 
hemispherical end-cap located at $0.30 \mathrm{~m}$ above the horizontal center line of the tunnel. Laser L1 detected smaller displacements (about $5 \mathrm{~mm}$ ) than the axial displacement measured at the tip of the plug, suggesting that the end-cap tended to change its original hemispherical shape to a slightly elliptical shape as the plug slipped. This pattern of sudden axial displacements at slippage was observed in all the sequences and for the other combinations of pressures used during the tests as illustrated in Figs. 14 and 15.

A summary of test results for sequence A-1 is shown in Table 6. From this summary, it can be seen that although the pressure differential (difference between plug and reached tunnel pressures) increased with an increase in the target slippage pressure, the ratio of $p_{\mathrm{re}} / p_{\mathrm{i}}$ (holding resistance ratio) remained approximately constant around an average of 0.78 . Test \#2 and Test \#3 showed a gradual increase of the ratio with the increase in $p_{\mathrm{e}}$ levels, but cannot be termed as definitive due to the closeness of the values. This relatively small variability of the ratios can be also attributed to the run-to-run variations originated by the multiple repetitions of the tests. These results indicate that the inflatable plug slipped when the external pressure was around 78 percent of the internal pressure for external pressures $p_{\mathrm{e}}$ in the range of 207 to $345 \mathrm{kPag}$. These results also mean that the design ratio of $p_{\mathrm{e}} / p_{\mathrm{i}}=1$ required in the design process [1], was not reached and that the coefficient of friction used in the initial sizing was inappropriate.

\subsubsection{Sequence A-2}

For slippage tests conducted under sequence A-2, the pressure release port in the plug was kept shut, allowing the plug pressure to rise as the tunnel pressure increased at a rate in the range of 0.34 to $0.55 \mathrm{kPag}$ per second. Figure 14 shows an example of results obtained for this sequence. This graph illustrates the effect of increasing the tunnel pressure while the plug pressure was not regulated. As seen in the graph, the plug pressure shows a steady increase with the increase in tunnel pressure until the differential becomes small enough, or equivalently, the ratio of external to internal
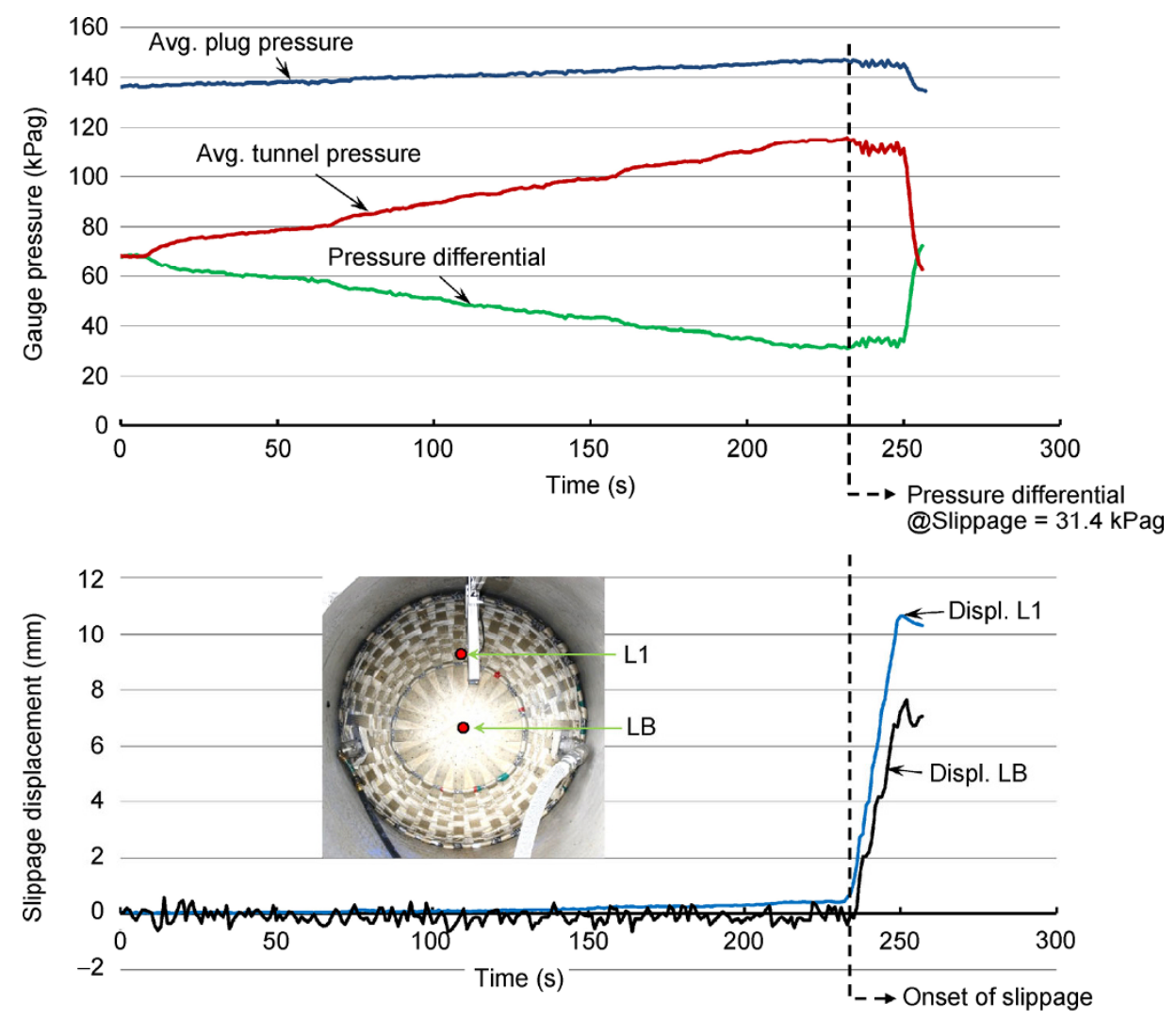

Fig. 14 Slippage Test: Sequence A-2, Test \#1, and tunnel pressure level 1. 

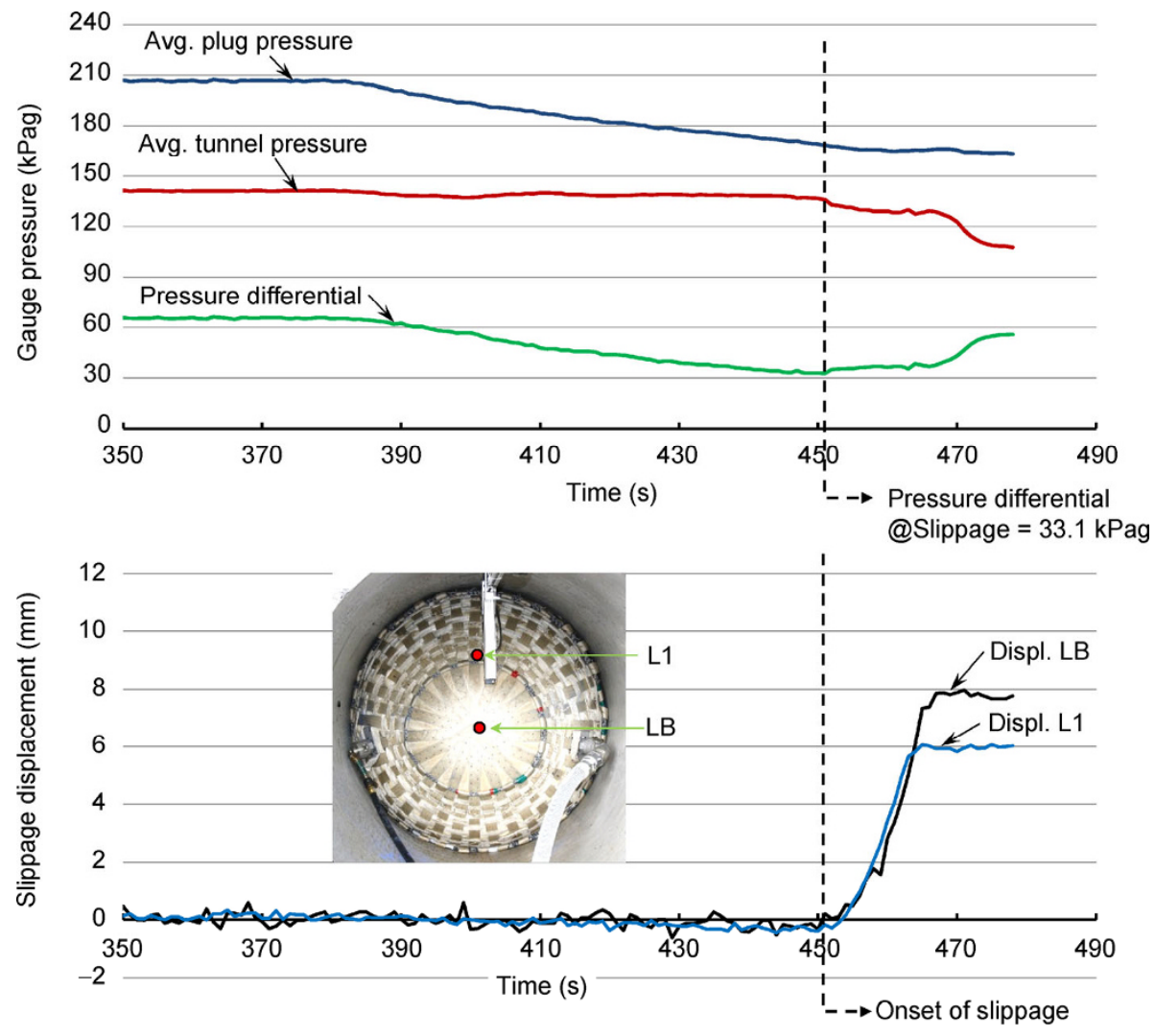

Fig. 15 Slippage Test: Sequence B, Test \#3, and plug pressure level 3.

Table 6 Summary of slippage tests for sequence A-1.

\begin{tabular}{|c|c|c|c|c|c|}
\hline \multirow{2}{*}{ Sequence A-1 } & $\begin{array}{l}\text { Plug pressure } \\
\text { CONSTANT }\end{array}$ & $\begin{array}{l}\text { Tunnel pressure } \\
\text { INCREASING } \\
\text { (Initial } \rightarrow \text { Target) }\end{array}$ & $\begin{array}{c}\text { Tunnel } \\
\text { pressure reached }\end{array}$ & $\begin{array}{l}\text { Pressure differential } \\
\text { at slippage }\end{array}$ & $\begin{array}{l}\text { Holding } \\
\text { resistance }\end{array}$ \\
\hline & $\begin{array}{c}p_{\mathrm{i}} \\
{[\mathrm{kPag}]}\end{array}$ & $\begin{array}{c}p_{\mathrm{e}} \\
{[\mathrm{kPag}]}\end{array}$ & $\begin{array}{c}p_{\mathrm{re}} \\
{[\mathrm{kPag}]}\end{array}$ & $\begin{array}{l}p_{\mathrm{i}}-p_{\mathrm{re}} \\
{[\mathrm{kPag}]}\end{array}$ & $\begin{array}{l}p_{\mathrm{re}} / p_{\mathrm{i}} \\
{[\%] \text { of } p_{\mathrm{i}}}\end{array}$ \\
\hline \multirow{3}{*}{ Test \#1 } & 207 & $138 \rightarrow 207$ & 164.1 & 42.7 & $79 \%$ \\
\hline & 276 & $207 \rightarrow 276$ & 219.3 & 56.5 & $80 \%$ \\
\hline & 345 & $207 \rightarrow 345$ & 259.9 & 84.8 & $75 \%$ \\
\hline \multirow{3}{*}{ Test \#2 } & 207 & $138 \rightarrow 207$ & 160.6 & 46.2 & $78 \%$ \\
\hline & 276 & $207 \rightarrow 276$ & 219.3 & 56.5 & $79 \%$ \\
\hline & 345 & $207 \rightarrow 345$ & 274.4 & 70.3 & $80 \%$ \\
\hline \multirow{3}{*}{ Test \#3 } & 207 & $138 \rightarrow 207$ & 155.8 & 51.0 & $75 \%$ \\
\hline & 276 & $207 \rightarrow 276$ & 215.8 & 60.0 & $78 \%$ \\
\hline & 345 & $207 \rightarrow 345$ & 270.3 & 74.5 & $78 \%$ \\
\hline Average & & & & 60.5 & $78 \%$ \\
\hline
\end{tabular}

pressure is large enough, for the plug to slip. Similar to what was observed in tests performed under sequence A-1, the onset of slippage was accompanied by an initial loud popping sound followed by con- tinuous, but not as loud, popping sounds as the plug moved horizontally, as illustrated in the sudden increase of displacement magnitude plotted in Fig. 14.

This set of experiments provided a measure of how 
much the plug pressure can increase with the increase in tunnel pressure and at what point the plug does slip. The percentage increase in plug pressure for each level of increase in tunnel pressure is summarized in Table 7. Results show that the increase of plug pressure ranged from 5 to 13 percent with an average of 8 percent for increases of tunnel pressures that ranged from 17 to 80 percent of the initial target value.

The holding resistance reached during the tests of sequence A-2 was on average 0.81 . That is, as in the previous sequence, the tunnel pressure reached only about 81 percent of the plug pressure before the plug slippage occurred. This was the highest ratio of external to internal pressure obtained from all slippage tests. Again, as in sequence A-1, these results mean that the design ratio of $p_{\mathrm{e}} / p_{\mathrm{i}}=1$ was not reached and that the assumed system coefficient of friction was incorrect.

\subsubsection{Sequence B}

This set of experiments was conducted to simulate depressurization of the inflatable plug due to a leak in the membrane or a failure of the plug pressurization system that leads to slippage of the plug. In this set of tests, the plug pressure was reduced by releasing water from the plug using a continuously adjusted water release valve to maintain a pressure reduction rate in the range of 0.55 to $0.70 \mathrm{kPag}$ per second, while maintaining the tunnel pressure constant. A summary of test results for sequence B is presented in Table 8 . An example of recorded data is presented in Fig. 15. Similarly to what was seen in the tests of sequences A-1 and A-2, the onset of slippage was accompanied by a popping sound indicative of horizontal displacement of the inflatable plug. At that point, there was a drop in the tunnel pressure due to an increase in tunnel volume immediately after slippage. The slippage of the plug showed all similar characteristics described in sequences A-1 and A-2.

For tests performed under sequence $\mathrm{B}$, there was a small increase in the holding resistance ratio to an average value of 0.8 . Comparing the average pressure differentials at slippage for all the sequences, it is seen that sequence A-1 (60.5 kPag) is slightly more conservative than sequence A-2 (41.8 kPag) and sequence B ( $50.5 \mathrm{kPag})$. However, when comparing the holding resistances, the percentages are very similar, ranging from 78 to 81 percent, which suggests that the slippage resistance of the system seems to be independent of the magnitude of the pressures and independent of the sequence of pressurization or depressurization used to induce the slippage. This behavior is consistent and analogous to tests results at coupon level in which the static friction coefficient is independent of the magnitude of the normal and horizontal forces measured during the tests. Considering that the inflatable plug was designed to fail

Table 7 Summary of slippage tests for sequence A-2.

\begin{tabular}{|c|c|c|c|c|c|c|c|c|}
\hline Sequence A-2 & $\begin{array}{c}\text { Plug } \\
\text { Pressure initially } \\
\text { CONSTANT @ } \\
p_{\mathrm{i}} \\
{[\mathrm{kPa}]}\end{array}$ & $\begin{array}{c}\text { Tunnel pressure } \\
\text { INCREASING } \\
\text { (Initial } \rightarrow \text { Target) } \\
p_{\mathrm{e}} \\
{[\mathrm{kPa}]}\end{array}$ & $\begin{array}{c}\text { Initial } \\
\text { tunnel } \\
\text { pressure } \\
p_{\mathrm{e}} \\
{[\mathrm{kPa}]}\end{array}$ & $\begin{array}{c}\text { Tunnel } \\
\text { pressure } \\
\text { reached } \\
p_{\text {re }} \\
{[\mathrm{kPa}]}\end{array}$ & $\begin{array}{c}\text { Plug } \\
\text { pressure } \\
\text { reached } \\
p_{\text {ri }} \\
{[\mathrm{kPa}]}\end{array}$ & $\begin{array}{c}\text { Pressure } \\
\text { differential } \\
\text { at slippage } \\
p_{\mathrm{ri}}-p_{\mathrm{re}} \\
{[\mathrm{kPa}]}\end{array}$ & $\begin{array}{c}\text { Holding } \\
\text { resistance }(\% \text { of } \\
\text { plug pressure) } \\
p_{\text {re }} / p_{\text {ri }} \\
{[\%]}\end{array}$ & $\begin{array}{c}\text { Increase } \\
\text { of plug } \\
\text { pressure } \\
\\
{[\%]}\end{array}$ \\
\hline \multirow{3}{*}{ Test \#1 } & 138 & $69 \rightarrow 138$ & 68.9 & 115.6 & 147.1 & 31.4 & $79 \%$ & $7 \%$ \\
\hline & 207 & $138 \rightarrow 207$ & 136.5 & 177.7 & 222.4 & 44.6 & $80 \%$ & $8 \%$ \\
\hline & 276 & $172 \rightarrow 276$ & 172.4 & 240.7 & 294.2 & 53.5 & $82 \%$ & $7 \%$ \\
\hline \multirow{3}{*}{ Test \#2 } & 138 & $69 \rightarrow 138$ & 68.9 & 124.0 & 153.0 & 29.0 & $81 \%$ & $11 \%$ \\
\hline & 207 & $138 \rightarrow 207$ & 150.3 & 176.4 & 216.8 & 40.5 & $81 \%$ & $5 \%$ \\
\hline & 276 & $172 \rightarrow 276$ & 180.6 & 237.7 & 294.1 & 56.3 & $81 \%$ & $7 \%$ \\
\hline \multirow{3}{*}{ Test \#3 } & 138 & $69 \rightarrow 138$ & 73.8 & 126.0 & 155.6 & 29.6 & $81 \%$ & $13 \%$ \\
\hline & 207 & $138 \rightarrow 207$ & 137.9 & 186.4 & 226.7 & 40.3 & $82 \%$ & $10 \%$ \\
\hline & 276 & $172 \rightarrow 276$ & 172.4 & 252.8 & 303.5 & 50.7 & $83 \%$ & $10 \%$ \\
\hline Average & & & & & & 41.8 & $81 \%$ & $9 \%$ \\
\hline
\end{tabular}


Table 8 Summary of slippage tests for sequence B.

\begin{tabular}{|c|c|c|c|c|c|}
\hline \multirow{2}{*}{ Sequence B } & $\begin{array}{l}\text { Plug pressure } \\
\text { DECREASING } \\
\text { (Initial } \rightarrow \text { Target) }\end{array}$ & $\begin{array}{l}\text { Tunnel pressure } \\
\text { CONSTANT }\end{array}$ & $\begin{array}{l}\text { Plug pressure } \\
\text { reached }\end{array}$ & $\begin{array}{l}\text { Pressure differential } \\
\text { at slippage }\end{array}$ & Holding resistance \\
\hline & $\begin{array}{c}p_{\mathrm{i}} \\
{[\mathrm{kPag}]}\end{array}$ & $\begin{array}{c}p_{\mathrm{e}} \\
{[\mathrm{kPag}]}\end{array}$ & $\begin{array}{c}p_{\text {ri }} \\
{[\mathrm{kPag}]}\end{array}$ & $\begin{array}{l}p_{\mathrm{ri}-} p_{\mathrm{e}} \\
{[\mathrm{kPag}]}\end{array}$ & $\begin{array}{c}p_{\mathrm{e}} / p_{\mathrm{ri}} \\
{[\%] \text { of plug }} \\
\text { pressure }\end{array}$ \\
\hline \multirow{3}{*}{ Test \#1 } & $379 \rightarrow 276$ & 276 & 343.4 & 67.6 & $80 \%$ \\
\hline & $276 \rightarrow 207$ & 207 & 260.6 & 53.8 & $79 \%$ \\
\hline & $207 \rightarrow 138$ & 138 & 175.8 & 37.9 & $78 \%$ \\
\hline \multirow{3}{*}{ Test \#2 } & $379 \rightarrow 276$ & 276 & 337.8 & 62.1 & $82 \%$ \\
\hline & $276 \rightarrow 207$ & 207 & 259.9 & 53.1 & $80 \%$ \\
\hline & $207 \rightarrow 138$ & 138 & 169.6 & 31.7 & $81 \%$ \\
\hline \multirow{3}{*}{ Test \#3 } & $379 \rightarrow 276$ & 276 & 342.0 & 66.2 & $81 \%$ \\
\hline & $276 \rightarrow 207$ & 207 & 256.5 & 49.6 & $81 \%$ \\
\hline & $207 \rightarrow 138$ & 138 & 171.0 & 33.1 & $81 \%$ \\
\hline Average & & & & 50.5 & $80 \%$ \\
\hline
\end{tabular}

by slipping at a pressure ratio of $p_{\mathrm{e}} / p_{\mathrm{i}}=1$, none of the testing sequences were able to reach such a ratio. The reevaluation of the system friction coefficient is presented in the next section.

\subsection{Friction coefficient for reduced-scale system}

In the plugging systems illustrated in Fig. 1 (full-scale) and Fig. 12 (reduced-scale), the onset of slippage of the inflatable plug is a function of the following forces: the total horizontal force, which is originated by the external pressure $p_{\mathrm{e}}$ and applied onto the surface of the plug's submerged end-cap; this force is equilibrated by shear forces distributed along the contact between the cylindrical part of the inflatable plug and the tunnel wall. These shear forces are proportional to the total normal force generated by the internal pressure $p_{\mathrm{i}}$ applied onto the inner surface of the inflatable plug. The proportionality factor is the static friction coefficient of the system [1]. With this consideration, the contact length of the reduced-scale inflatable was obtained by:

$$
L=\left(\frac{p_{\mathrm{e}}}{p_{\mathrm{i}}}\right)\left(\frac{R}{2 \mu}\right)=1.14 \mathrm{~m}
$$

where $R=0.61 \mathrm{~m}$ is the radius of the cylindrical part of the inflatable and $\mu=0.27$ is the friction coefficient obtained from coupon tests. The length $L=1.14 \mathrm{~m}$ was obtained with the assumption that the ratio $p_{\mathrm{e}} / p_{\mathrm{i}}=1$ will be the most critical pressure combination that the inflatable structure will have to endure to stay in place. However, from measurements performed during the tests, it was found that the actual contact length of the cylindrical part of the plug with the tunnel wall was $L^{*} \approx 1.27 \mathrm{~m}$. This slight increase is due to the confining effect of the pipe on the hemispherical endcaps that contributed to contact length. Then, Eq. (2) is rearranged to find the friction coefficient of the system as a function of the variables measured experimentally as follows:

$$
\mu_{\mathrm{S}}=\left(\frac{p_{\mathrm{e}}}{p_{\mathrm{i}}}\right)_{\exp }\left(\frac{R}{2 L^{*}}\right)
$$

where $\left(p_{\mathrm{e}} / p_{\mathrm{i}}\right)_{\exp }$ is obtained from Tables 6, 7, and 8. Eq. (3) was used to compute $\mu_{\mathrm{S}}$ without taking into account the hydrostatic variation of the pressures. That is, the computations assume that the pressure is applied uniformly at all points, which is the most conservative scenario. This assumption is considered to be reasonable given the dimensions of the concrete tube $(1.22 \mathrm{~m})$ and the magnitude of the pressures applied during the tests, which ranged from $138 \mathrm{kPag}$ to $379 \mathrm{kPag}$ as measured at the base of the inner surface of the concrete tube. The maximum pressure difference between the top and bottom that would be expected 
is $12 \mathrm{kPag}$. The system friction coefficients based on the tests results obtained from sequences A-1, A-2, and B are summarized in Table 9.

From Table 9, the minimum average system friction coefficient corresponds to sequence A-1 with a value of 0.187. For sequences $\mathrm{A}-2$ and $\mathrm{B}$, the average coefficients resulted in values of 0.195 and 0.193, respectively. The overall average system friction coefficient considering all the testing sequences is 0.192 . This value is about 29 percent lower than the value used for the design.

In order to identify the factors that could explain the difference of results at different scales, it is necessary first to reiterate what is being compared. At coupon level, single and woven Vectran webbings were rubbed against flat smooth concrete in order to determine the friction coefficient under dry and wet conditions. At reduced-scale level, a prototype of an inflatable plug was built using the same Vectran material to form the membrane that is contact with the smooth concrete surface of a concrete pipe. The length of the cylindrical portion of the inflatable plug was determined using one of the friction values obtained at coupon level. The slippage characteristics of the reduced-scale inflatable plug were evaluated with pressurized water. Then, tests results at coupon level (summarized in Fig. 8) may have been affected by the following three factors:

(1) Size effect: The size of the specimens seems to influence the friction coefficient values. As pointed out in Section 2.6.2, the larger the area of contact the larger would be the value of the friction coefficient. This is evidenced in the friction coefficients for single webbings (nominal contact area of $26 \mathrm{~cm}^{2}$ and $\mu=$ 0.35 to 0.38 ) with respect to the values obtained for woven webbings (nominal contact area of $103 \mathrm{~cm}^{2}$ and $\mu=0.72$ ).

(2) Plowing effect: This effect is common when a rough, hard surface (provided by the concrete block) tend to slide over a soft surface (provided by the woven webbings). The plowing effect increases the frictional force and therefore the friction coefficient. However, in the set of tests reported in this work, the plowing effect is attributed more to the testing configuration in which the concrete block itself acts as a plow (see Fig. 7) rather than to the asperities of the harder surface. This effect could also be contributing to the large difference between test results of single webbings $(\mu=0.35-0.38)$ and woven webbings $(\mu=0.72)$.

(3) Wetting effect: Tests at coupon level were performed with specimens in contact with concrete surfaces in a soaking-wet environment. Since synthetic fibers like Vectran are typically hydrophobic, the effect of wetting is the result of penetration of water through the interstitial space between fibers and yarns that constitute the webbing itself that caused the yarns to swell to some extent. This effect led to an increase of the area of contact and, thus, in an increase of the friction coefficient [21]. This effect is evidenced in the results of single webbings tested in dry $(\mu=0.35)$ and

Table 9 System friction coefficients of the reduced-scale plugging system.

\begin{tabular}{|c|c|c|c|c|c|c|c|c|}
\hline \multirow{2}{*}{ Test \# } & \multirow{2}{*}{$\begin{array}{c}\text { Contact length } \\
L^{*} \\
{[\mathrm{~m}]}\end{array}$} & \multirow{2}{*}{$\begin{array}{c}\text { Radius } \\
R \\
{[\mathrm{~m}]}\end{array}$} & \multicolumn{2}{|c|}{ Sequence A-1 } & \multicolumn{2}{|c|}{ Sequence A-2 } & \multicolumn{2}{|c|}{ Sequence B } \\
\hline & & & $p_{\mathrm{e}} / p_{\mathrm{i}}$ & $\mu$ & $p_{\mathrm{e}} / p_{\mathrm{i}}$ & $\mu$ & $p_{\mathrm{e}} / p_{\mathrm{i}}$ & $\mu$ \\
\hline \multirow{3}{*}{ Test \#1 } & \multirow{3}{*}{1.27} & \multirow{3}{*}{0.61} & 0.792 & 0.190 & 0.786 & 0.189 & 0.803 & 0.193 \\
\hline & & & 0.795 & 0.191 & 0.799 & 0.192 & 0.793 & 0.190 \\
\hline & & & 0.754 & 0.181 & 0.818 & 0.196 & 0.784 & 0.188 \\
\hline \multirow{3}{*}{ Test \#2 } & \multirow{3}{*}{1.27} & \multirow{3}{*}{0.61} & 0.775 & 0.186 & 0.810 & 0.194 & 0.817 & 0.196 \\
\hline & & & 0.795 & 0.191 & 0.813 & 0.195 & 0.795 & 0.191 \\
\hline & & & 0.795 & 0.191 & 0.808 & 0.194 & 0.814 & 0.195 \\
\hline \multirow{3}{*}{ Test \#3 } & \multirow{3}{*}{1.27} & \multirow{3}{*}{0.61} & 0.752 & 0.180 & 0.810 & 0.194 & 0.807 & 0.194 \\
\hline & & & 0.782 & 0.188 & 0.822 & 0.197 & 0.806 & 0.193 \\
\hline & & & 0.784 & 0.188 & 0.833 & 0.200 & 0.807 & 0.194 \\
\hline Average & & & 0.780 & 0.187 & 0.811 & 0.195 & 0.803 & 0.193 \\
\hline
\end{tabular}


wet $(\mu=0.38)$ conditions.

On the other side, tests results at reduced-scale level (summarized in Table 9) may have been influenced predominantly by the following two factors:

(1) Curvature and area of contact: The contact surface of tests at reduced-scale had a curvature of $1 / r$, where $r=0.61 \mathrm{~m}$ is the inner radius of the pipe used for the tests, while tests at coupon level where performed on flat surfaces for which the area of contact was, at least in theory, optimal. It is also speculated that the area of contact may be influenced by the mechanisms used for applying the normal load at the coupon and reduced-scale levels. At the coupon scale, the normal load was applied thorough a metal road (see Fig. 7), whereas for the reduced scale tests the normal load was applied using pressurized water (see Fig. 11). The area of contact of the coupon level tests would seem to be the result of the Vectran webbing being deformed on the flat surface and based on the magnitude of the normal load. In the reduced scale tests, the area of contact would be the result of the equilibrium between the external Vectran webbings and the inner bladder on which the internal pressure is applied. Moreover, in the tests at reducedscale, the correct initial positioning of the inflatable plug was crucial for maximizing the area of contact and reduced the formation of membrane bridges originated by misplacement and aggravated by the curvature of the pipe. Therefore, considering that the friction coefficient tends to increase as the area of contact increases, any lack of contact originated by misalignment or bridging of the membrane certainly may have reduced the extent of actual contact and thus the value of friction coefficient estimated at system level. Moreover, the actual contact may have been influenced by actual contact perimeter of the cylindrical portion of the reduced-scale inflatable plug. In order to account for possible manufacturing imperfections, the perimeter of the cylindrical segment was oversized $2 \%$. However, this percentage of oversize may not be sufficient to makeup imperfections or reductions in the actual area of contact when the initial positioning is not optimal. Then, it is speculated that the holding capacity or slippage resistance of the inflatable plug may have been affected by insufficient or imperfect contact with the pipe inner wall.
(2) Leakage pressure: Since primary function of the inflatable plug is to stop the propagation of flooding, the containment of the external pressure generated by water acting on one side the plug (see Fig. 11) is paramount for the success of the system. However, because of the texture of the membrane on contact with the tunnel walls (see Figs. 2 and 9) the contact is not perfect. The macro-fabric of woven webbings creates a wavy pattern that allows water to leak through the webbing interstices. The pressure of the water leaking through the interphase between the woven webbings and the tunnel wall is similar to the pore or interstitial pressure present in saturated soils. Preliminary tests to determine the magnitude and distribution of the leakage pressure indicated that it followed a linear distribution along the contact length with a maximum in the submerged or "wet" side of the plug and a minimum of zero in the "dry" side of the plug (see Fig. 11). In a 3D space, this leakage pressure can be seen as a cone of water pressure that opposes the internal or inflation pressure of the inflatable plug. This effect would be equivalent to a reduction of the normal pressure which in turn reduces the area of contact and therefore the frictional resistance and ultimately the friction coefficient at reduced-scale level. In a certain way, the leaking water and leakage pressure can be seen as a hydrodynamic lubricant that reduces friction. On the contrary, although tests at coupon level were performed at in soaked-wet conditions, the leakage pressure effect is not present since water is not pressurized, and the normal pressure tends to expel water from the area of contact, thus minimizing the chances of water to act as a lubricant.

In summary, the two main factors that are possibly influencing the most in the determination of the friction coefficient at the different scales are the actual area of contact and the presence or not of pressurized water leaking at the wall contact interface. Additional tests will be needed to determine which one is the most dominant.

\section{Conclusions}

Two sets of tests were conducted in order to find frictional characteristics of Vectran webbings used as the main structural component of the membrane of 
confined inflatable structures designed for protection of underground tunnels or large conduits.

Tests at coupon level indicate that: (1) For specimens of single webbings rubbing over other webbing, the friction coefficient is the smallest of all the values obtained at coupon level. (2) For single webbing specimens rubbing over concrete surfaces, test results indicate that the friction coefficient for smooth concrete is about $42 \%$ lower than the values obtained on tests performed over rough concrete. (3) Tests with three by four woven webbings rubbing over concrete surfaces predicted the highest values of friction coefficient of the whole set of tests at coupon level. Friction coefficient values were in the range of $72 \%$ to $95 \%$ higher than values obtained with single webbing specimens; however, these values are overestimated due to the plowing effect caused by the testing configuration used for this particular set of specimens.

Tests with a reduced-scale inflatable structure showed that the system friction coefficient derived from slippage tests performed for different combinations of pressures and pressurization sequences was about 29 percent lower than values obtained at coupon level for single webbings.

Possible sources of difference include the scale effect, the pressure of water leaking through the texture of the macro-fabric created by the woven webbings, and the actual degree of contact at the interphase between the woven webbings and the confining surface.

Future engineering designs of confined inflatable structures for containing flooding pressures can find useful the following insight obtained from the present work:

(1) Friction tests at coupon level of a single webbing provide an initial estimation of the friction coefficient that can be used to determine the contact length of the inflatable plug. This type of test is very common, relatively simple and fast to perform, and it can be used to determine friction values for different types of contact surfaces and different types of webbing material.

(2) Friction tests at coupon level of a specimen of woven webbings require more material and additional preparation work to create an accurate testing specimen. Moreover, the testing configuration can affect the results and may overestimate the friction coefficient resulting in values not conservative for the design. If using a reduced-scale prototype is not an option, tests at this level could be used for evaluation of the friction characteristics of a segment of the actual membrane in contact with a portion of the confining surface. However, additional adjustments of the testing machine and testing specimens may be necessary in order to obtain meaningful and realistic results.

(3) Friction or slippage tests with a reduced-scale prototype provide better preliminary overall system evaluation of the performance of the design and not just individual components. Tests at this level involve manufacturing details, loads and operational conditions that can be expected in full-scale prototypes or in the actual operational units expected to be installed in the field. With no doubt, tests at reduced-scale are more complex and require significantly more time for preparation and execution than coupon tests. Although, they may not be able to capture all of the physical features of a full-scale system, certainly they can provide controlled scenarios for the assessment of the performance of specific design parameters before much more complex evaluations at full-scale. Moreover, tests results at reduced scale can be used to determine adjustment factors-for the friction coefficient or the area of contact or for other parameters - that can be applied to the values obtained at coupon level and implemented in future designs. The scale model results also provide data that can be used as a foundation to develop analytical or empirical models of these structures.

\section{Acknowledgments}

This work was sponsored by the U.S. Department of Homeland Security Science and Technology Directorate (S\&T) Homeland Security Advanced Research Projects Agency (HSARPA). The reduced-scale inflatable plug was manufactured by ILC Dover.

Open Access: This article is distributed under the terms of the Creative Commons Attribution License which permits any use, distribution, and reproduction in any medium, provided the original author(s) and source are credited. 


\section{References}

[1] Barbero E J, Sosa E M, Martinez X, Gutierrez J M. Reliability design methodology for confined high pressure inflatable structures. Eng Struct 51: 1-9 (2013)

[2] The Blue Ribbon Panel on Bridge and Tunnel Security. Recommendations for bridge and tunnel security. Publication FHWA-IF-03-036. U.S. Department of Transportation, 2003.

[3] Rabkin N. Passenger rail security, federal strategy and enhanced coordination needed to prioritize and guide aecurity efforts. Publication GAO-07-583T, U.S. Government Accountability Office, 2007.

[4] Inouye RJacobazzi J. The great Chicago flood of 1992. Civil Engineering-ASCE 62: 52-55 (1992)

[5] Post, Buckley, Schuh, and Jernigan, Inc. Hurricane Isabel assessment, a review of hurricane evacuation study products and other aspects of the national hurricane mitigation and preparedness program (NHMPP) in the context of the hurricane Isabel pesponse. National Oceanic Atmospheric Administration, 2005.

[6] The City of New York. A stronger, more resilient new york. http://www.nyc.gov/html/sirr/html/report/report.shtml, 2013.

[7] Lindstrand Technologies. Inflatable tunnel plugs. http://www.lindstrandtech.com/innovation-centre-main/inn ovation-centre/inflatable-tunnel-plugs/, 2014.

[8] Stocking A. An inflatable tunnel seal stops flooding of world's largest undeveloped uranium mine.

http://www.petersenproducts.com/case_study/Large_Mine_ Flooding_Remediation.aspx, 2013.

[9] Barrie A. Going underground: Homeland security works on tool to prevent tunnel disasters.

http://www.foxnews.com/story/0,2933,417461,00.html, 2013.

[10] Martinez X, Davalos J, Barbero E, Sosa E, Huebsch W, Means K, Banta L, Thompson G. Inflatable plug for threat mitigation in transportation tunnels. In Proceedings of the Society for the Advancement of Material and Process Engineering (SAMPE) 2012 Conference, Baltimore, Maryland, USA, 2012.

[11] Barbero E J, Sosa E M, Thompson G J. Testing of full-scale confined inflatable for the protection of tunnels. In Proceedings of the VI International Conference on Textile Composites and Inflatable Structures, Structural Membranes 2013, Munich, Germany, 2013.

[12] Sosa E M, Thompson G J, Barbero E J. Testing of full-scale inflatable plug for flood mitigation in tunnels. Transportation Research Record: Journal of the Transportation Research Board, Structures 2: 59-67 (2014)
[13] Fountain H. Holding back floodwaters with a balloon. The New York Times Science Supplement. http://www.nytimes.com/2012/11/20/science/creating-a-ball oonlike-plug-to-hold-back-floodwaters.html, 2012.

[14] Paggi M, Carpinteri A. Size-scale effects on the friction coefficient: From weak faults at the planetary scale to superlubricity at the nanoscale. Recent Advances in Contact Mechanics, LNACM 56: 67-84 (2009)

[15] Bhushan B, Nosonovsky M. Scale effect in mechanical properties and tribology. In Springer Handbook of Nanothechnology, 3rd Edition, Part D, 33: 1023-1054, 2010.

[16] Bhushan B, Nosonovsky M. Scale effects in dry and wet friction, wear and interface temperature. Nanotechnology 15: 749-761 (2004)

[17] Chiaia B. On the sliding instabilities at rough surfaces. $J$ Mech Phys Solids 50: 895-924 (2002)

[18] Coulomb C A. Théories des machines simples, en ayant égard au frottement de leurs parties et à la roideur des cordages. In Mémoire de Mathématique et de Physique de l'Académie Royale, New Edition, Part 1, Chapter III. Paris, France, 1785: 99-105.

[19] Amontons G. De la résistance causée dans les machines. In Mémoires de l'Académie Royale, Histoire de l'Académie Royale des Sciences, 1732: 206-227.

[20] Bowden F P, Tabor D. The Friction and Lubrication of Solids. Oxford, Clarendon Press, 1954.

[21] Gupta B S. Friction in Textile Materials. Boca Raton, Florida (USA): CRC Press (2008)

[22] Kovar P, Gupta B S, Kus Z. Stick-slip phenomena in textiles. In Friction in Textile Materials. Boca Raton, Florida (USA): CRC Press, 2008.

[23] Hinkle J, Cadogan D, Roushey J, and Cook R. Design and testing of a resilient expandable structure using multi-layer softgoods technology. In Proceedings of the AIAA/ASME/ ASCE Structures, Dynamics, and Materials, Honolulu, Hawaii, USA, 2012.

[24] Kuraray Co. Homeland security: A big plug for Vectran. http://www.vectranfiber.com/NewsInformation/tabid/83/En tryId/23/Homeland-Security-A-Big-Plug-for-Vectran.aspx, 2014.

[25] ICRI Technical Guidelines No. 310.2-1997. Selecting and specifying concrete surface preparation for sealers, coatings, and polymer overlays. International Concrete Repair Institute (1997)

[26] Rabinowicz E. Friction and Wear of Materials. New York (USA): Wiley (1995)

[27] Batchelor A W, Stachowiak G W. Revealing the hidden world of wear and friction. Mechanical Engineering 
Transactions, Journal of the Institute of Engineers 20(1): 5-13 (1995)

[28] El-Mogahzy Y E, Gupta B S. Friction in fibrous materials. Part II: Experimental study of the effects of structural and morphological factors. Text Res J 63: 219 (1993)

[29] Allaoui S, Hivet G, Wendling A, Ouagne P, Soulat D. Influence of the dry woven fabrics meso-structure on

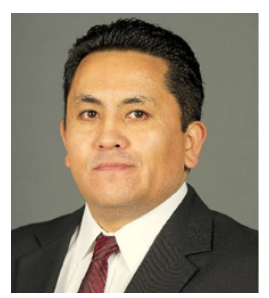

Eduardo M. SOSA. He received his Ph.D. degree in Civil Engineering from the University of Puerto Rico, USA, in 2005. Soon after he joined West Virginia University, first as postdoctoral research fellow in the Department of Mechanical and

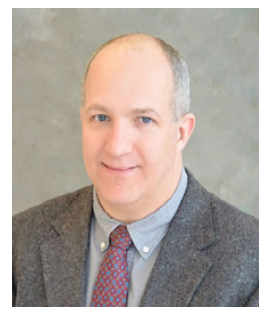

Gregory J. THOMPSON. He received his Ph.D. degree in Mechanical Engineering from the West Virginia University, USA, in 1995. Soon after he joined West Virginia University,

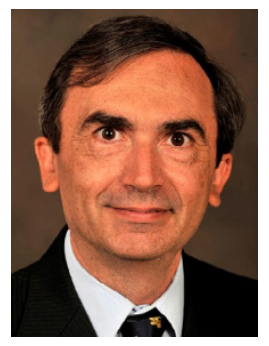

Ever J. BARBERO. He received his $\mathrm{Ph} . \mathrm{D}$. degree in Engineering Mechanics from Virginia Tech, USA, in 1986. He is Fellow of ASME and SAMPE, Professor of Mechanical and Aerospace Engineering at West Virginia University, and honorary fabric/fabric contact behavior. J Compos Mater 46: 627-639 (2012)

[30] Akay A. Acoustics of friction. Journal of the Acoustical Society of America 111: 1525-1548 (2002)

[31] Le Bot A, Bou Chakra E. Measurement of friction noise versus contact area of rough surfaces weakly loaded. Tribol Lett 37: 273-281 (2010)

Aerospace Engineering, and then as Research Assistant Professor at the Department of Civil and Environmental Engineering. His research areas include rapidly deployable structures and materials for protection of tunnels and other civil infrastructure, structural membranes as well as stability of thinwalled structures.

first as a research assistant professor and then as a assistant professor in the Department of Mechanical and Aerospace Engineering. His research areas include mechanisms, machines, and thermodynamic analysis of systems.

Professor at Universidad Carlos III de Madrid (Spain), University of Puerto Rico (PR), and Universidad Nacional de Trujillo (Peru). His research interests encompass materials modelling and characterization. He is author of several books including Introduction to Composite Materials Design and Finite Element Analysis of Composite Materials. 